\title{
أثر السياسة الزراعية علي أهم المؤثرات الإقتصادية لمحصول البصل في مصر
}

\author{
حسام الاين محمد صديق \\ قسم العلوم الاقتصادية التعاونية الزراعية- المعهد العالي للتعاون الزراعي.
}

Received: May . 14, 2017

Accepted: May 29, 2017

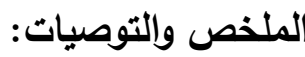

يعتبر محصول البصل من أهم محاصيل الخضر الرئبيية التي تترع في مصر، سواء علي مستوي الإستهلاك المحلي أو

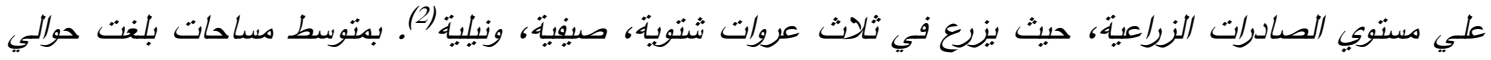
(101، 13، 11) ألف فدان علي الترتيب، تمثل نحو 80.8\%، 10.4\%، 8.8\% من منوسط إجمالي الدساحة المنزرعة

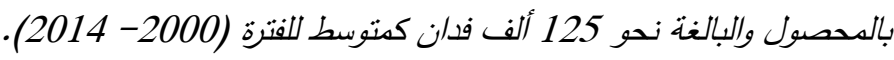
وإستهدف البحث بصفة أساسية البي تحليل السياسات الزراعبة لمحصول البصل في مصر، وتحديد دور الدولة في كفاءة استخدام الدوارد المتاحة. كما إعتد البحث في الحصول علي بياناته وفق معطيات التسلسل الزني لها خلا فترة الدراسة (2000- 2014)، من خلال العديد من الجهات مثل وزارة الزراعة وإستصلاح الأراضي، قطاع الثئون الإقتصادية، الإدراة

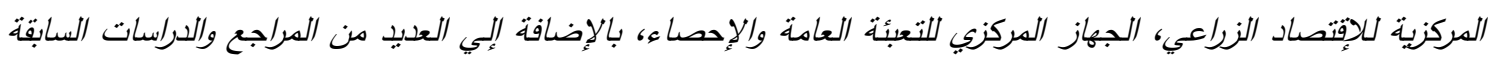

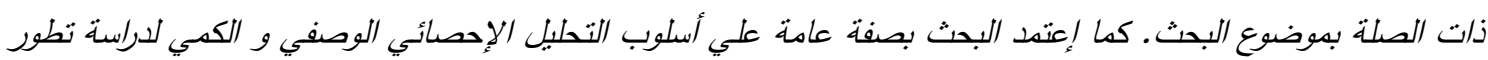

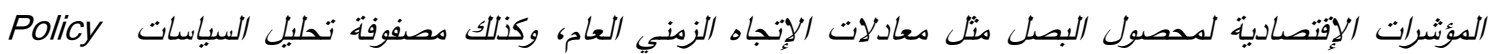
(PAM) analysis matrix

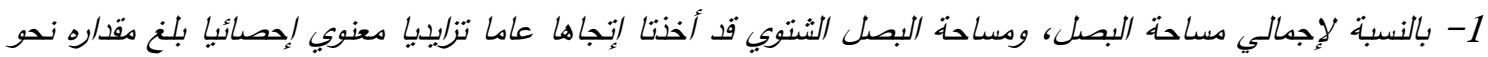

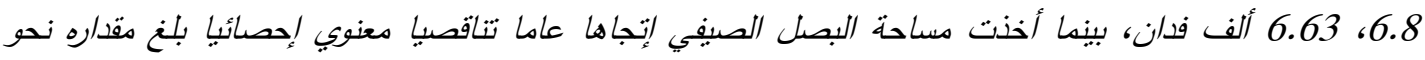

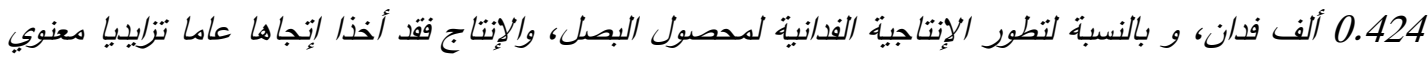

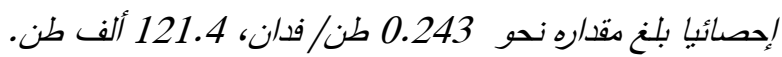
2- وبالنسبة (تكلفة العمل البشري، نكلفة العمل الآلي، تكلفة الدصروفات العدومية، الإيجار) قد أخذت إتجاها عاما تنزايديا معنوي إحصائيا بلغ مقداره نحو (41.88، 18.1، 9.06،

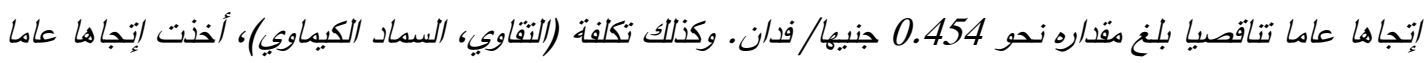
تنزيبيا معنوي إحصائيا بلغ مقداره نحو (15.83، 21.94) جنيها/ فدان. بينها كانت تكلفة السهاد البلدي، وتكلفة

$$
\text { المبيد/ت غبير معنوية إحصائيا. }
$$

3- وبالنسبة لكل من (إجمالي النكاليف، السعر المزرعي، إجمالي الإيراد، صافي العائد) فقد أخذت إتجاها عاما تنزايديا

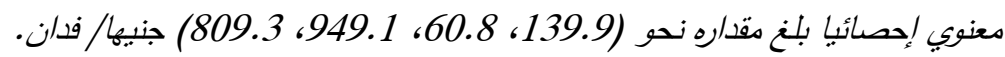
4- وبالنسبة لمعامل الحماية الإسي للنواتج (الهخرجات) فقد كان أقل من الواحد الصحيح وهذا بعني أن الدولة تتلذخل لحماية إنتاج الدحصول في السوق الدملي. 5 - وبالنسبة لمعامل الحماية الإسدي لمستلزمات الإنتاج (الددخلات) الدتاجر فيها فقد تبين أنه كان أقل من الواحد الصحيح

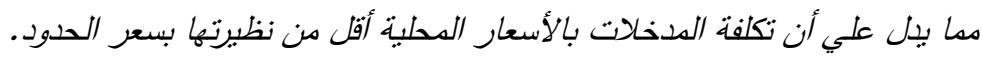

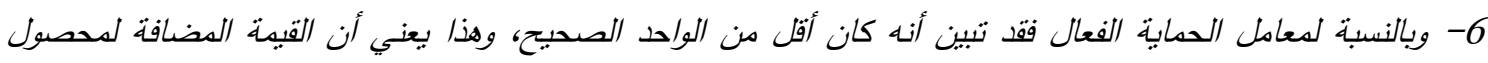
البصل بالأسعار الدحلية تقل عن نظيزتها بالأسعار العالمبة، وهناك ضرائب ضنية يتحملها منتجوا البصل خلال فترة الدراسة. 


\section{H. M. M. Seddik}

7- وبالنسبة لمعامل نكلفة الموارد الدحلية (المبيزة النسبية) فقد كان أقل من الواحد الصحيح، ما بئكد علي العبزة النسبية التي

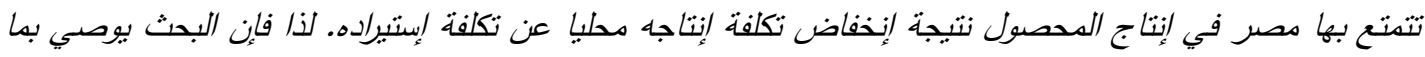

1- العمل علي رفع الأسعار المزرعية لمحصول البصل بما يتناسب مع الزيادة الدستمرة في النكاليف الإنتاجية.

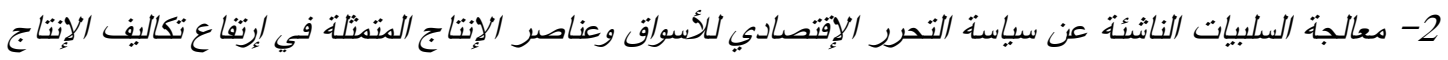
وإتاحتها بأسعار مناسبة. 3- العمل علي فتح أسواق جديدة لتصدير محصول البصل، بما يعود بالنفع العام علي المنارعين والدولة. الكلمات اللالثة: معامل الحماية الإسمي- معامل الحماية الفعال - معامل نكلفة الدوارد المحلية.

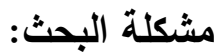
مقدمة:

إتجهت الحكومة المصرية منذ أوائل النصف الثاني من عقد الثمانينات إلي تحرير السياسـات الزراعيـة والإعتمـاد علـي آليـات السـوق الحـر ، واثــتملت عمليـة الإصـلاح الاقتصـادي علي عدد من الإجراءات تمشيا مـع برنـامج

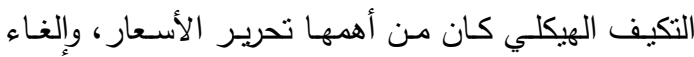

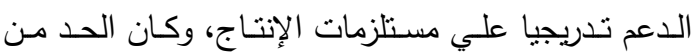
تدخل الدولة في الأنثطة الإنتاجية دافعا للقطاع الخاص الاص التان ليكون الربح هو الحافز للنشاط الاقتصـادي، وقد ظهرت الإناه

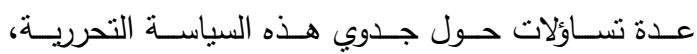
خصوصـا فيما يتعلق بإنعكاسـاتها علي مختلف الظواهر الإنتاجيـة والإقتصـادية لأهم المحاصيل الزراعيـة. وبنـاءاً

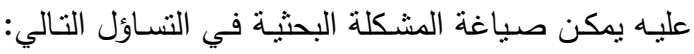
هل ترتب علي تطبيق سياسة الإصلاح الإقتصادي تحسين

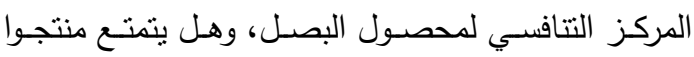

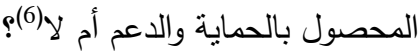

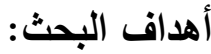

من المعروف أن تبديل أو تعديل أو تغيير أي سياسة إقتصادية يؤدي إلي ظهور العديد من الآثار الإقتصادية إئية

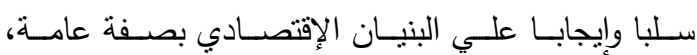
والزراعي بصفة خاصة، لذا يهدف البحث بصفة أساسية إلي تحليل السياسات الزراعية لمحصول البصل في مصر، وتحديد دور الدولـة في كفـاءة استخدام الموارد المتاحسة، وذلك من خلال تقدير حجم التحويلات النانشيء عن تبني الدولة لسياسة التحرر الإقتصادي والنعرف علي جوهر هذه

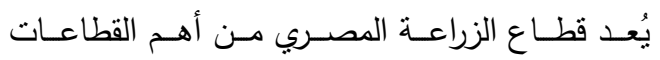

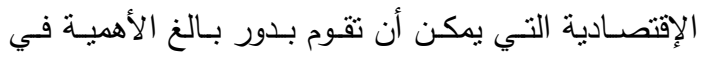

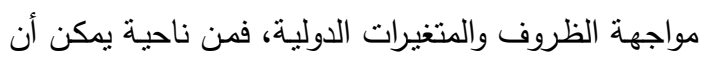

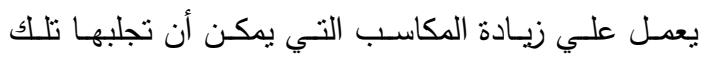
المتغيرات، ومن ناحية أخري يقلل من الآثار السلبية التي سوف تتتج من مثل هذه المتغيرات إلي أدني حد ممكن(2). هذا ويعتبر محصول البصل من أهم محاصيل الخضر الرئيسـية التــي تـزرع فـي مصـر ، سـواء علـي مسـتوبي الإستهلاك المحلي أو علي مسنوي الصـادرات الزراعيـة، حيث يزرع في ثلات عروات شتوية، صيفية، ونيلية(1، 3.

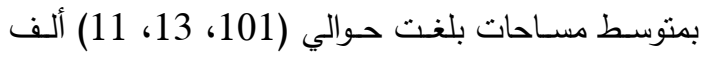

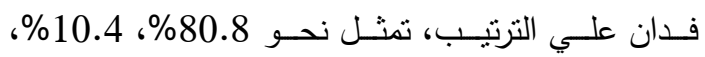
8.8 من متوسط إجمالي المساحة المنزرعة بالمحصول والبالغـة نحو 125 ألف فدان كمتوسط للفترة (20002014)(9). وتحتل صـادرات البصـل المرتبـة الثانيـة في كي مجموعة الصادرات المصرية من الخضر ، حيث تعد مصر مـن أهم الـدول المصدرة للبصـل خاصــة للـدول العربيـة

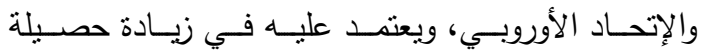

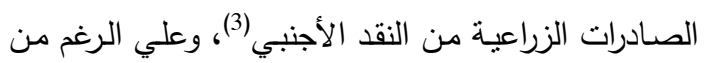

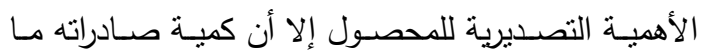
زالت ضئيلة حيث بلغت حوالي 316.69 ألف طن، تمثل

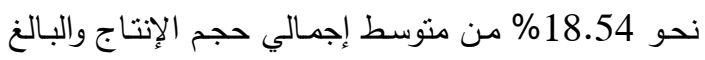
نحو 1708 ألف طن كمنوسط لفترة الدراسة(8). 
الإنتاج المتاجر فيها ماليا ب قيمة تكاليف مستلزمات الإنتاج المتاجر فيها إقتصاديا.

ولتفسير هذا المعامل يوجد ثلاث حالات هي:

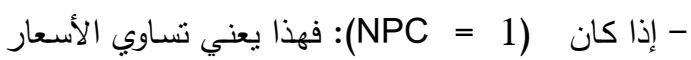

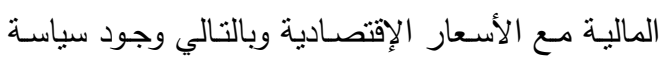

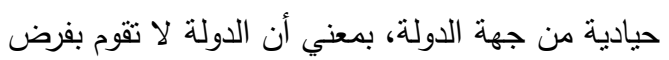

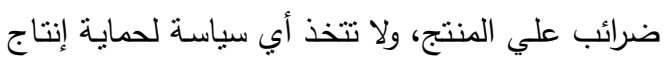

$$
\text { السلعة في السوق المحلي. }
$$

- إذا كان (NPC) > مهذا يعني وجود سياسـة

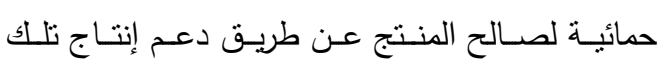
السلعة، حيث أن السعر المحلي يفوق السعر العالمي.

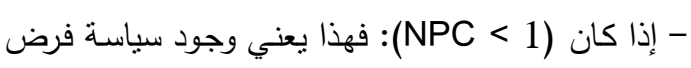
ضرائب ضمنية علي المنتج والعكس صحيح في تفسير هذا المعامل لمستلزمات الإنتاج.

Effective (EPC ) معامسل الحمايـة الفعـال (-3) protection coefficient

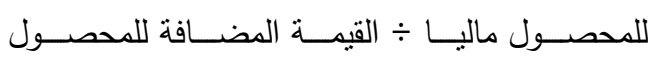
إقتصاديا. أو = (إجمالي إيراد الفدان ماليا - قيمة تكاليف مستلزمات

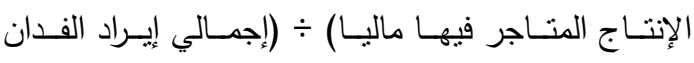
إقتصاديا - قيمة تكاليف مستلزمات الإنتاج المتاجر فيها (إقتصاديا).

وهـو المعامـل الذي يشـرح مـا يفسـره معامـل الحمايـة

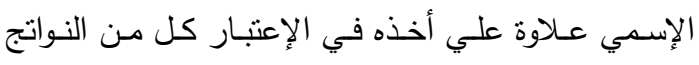

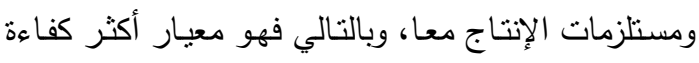

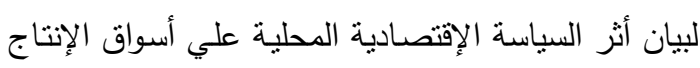
ومستلزماته.

4- معامـل تكلفـة المـوارد المحليـة أو الميـزة النسـبية = Domestic Resource Cost (DRC) تكلفـة المـورد المحلـي إقتصـاديا خ القيمـة المضــافة إقتصاديا.

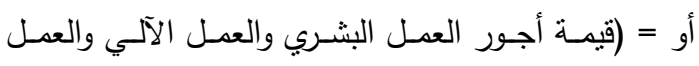

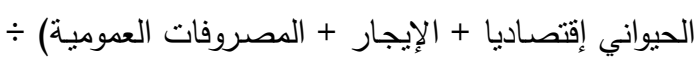

السياسات سواء كانت حمائية أو ضرائبية مباشرة، أو غير

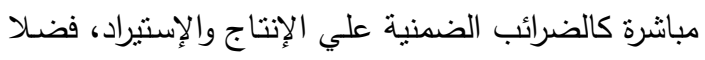
عن قياس مدي التشوهات السعرية المحلية لمعرفة مدي الإني إنحرافها عن الأسعار العالمية(4).

$$
\text { مصادر البيانات والأسلوب البحثي: }
$$

إعتمد البحث في الحصول علي بياناته وفق معطيات التسلسل الزمني لها خلال فتزة الدراسة (2000- 2014)، من خلال العديد من الجهات منل وزارة الزراعة وإستصلاح

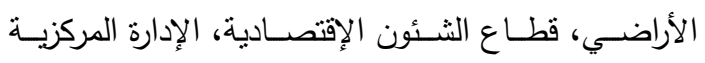

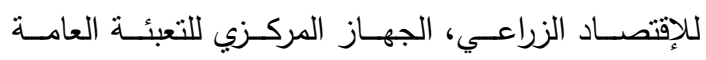

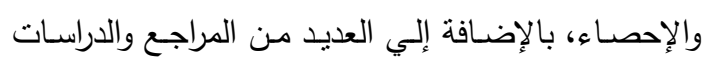
السابقة ذات الصلة بموضوع البحث.

كما إعتمد البحث بصفة عامـة علي أسلوب التحليل

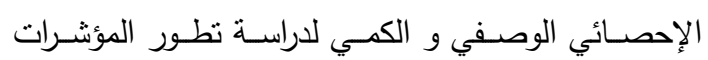
الإقتصادية لمحصول البصل مثل معادلات الإتجاه الزمني

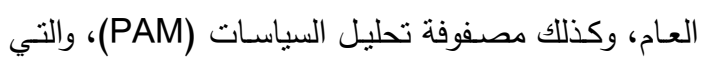
تهدف أساسا إلي تحليل تأثير سياسات تدخل الدولة، ومن العنانيات

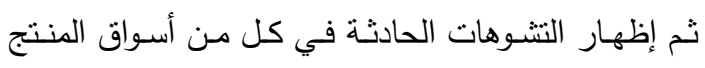
النهائي ومستلزمات الإنتاج، وذلك بتقدير معاملات الحماية

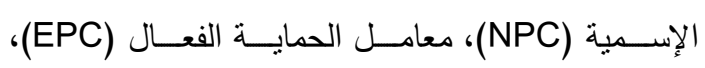

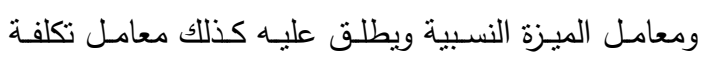

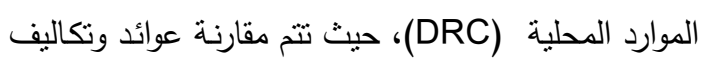

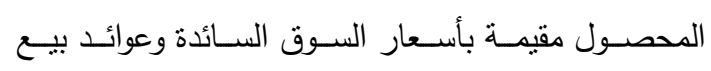

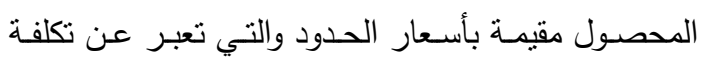
الفرصة البديلة للسلعة التي تدخل في التجارة الدولية. - المؤشرات الإتصادية لمصفوفة تحليل السياسات الزراعية

أ- معامل الحماية الإسي (NPC) protection coefficient 1- معامل الحماية الإسمي للنواتج = إجمالي إيراد الفدان ماليا ٪ إجمالي إيراد الفدان إقتصاديا.

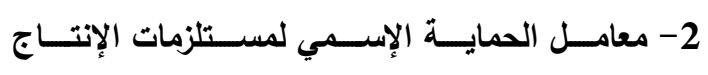

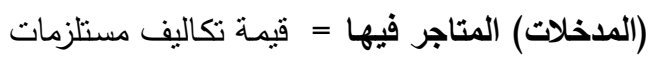


بمقدار نتزايـد بلـغ نحو 88 ألف فدان أيضـا، يمثل نحو

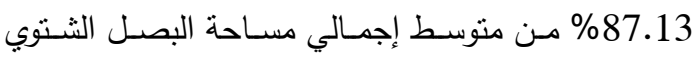

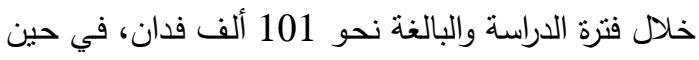
تتاقصت مساحة البصل الصيفي من نحو 12 ألف فدان عام 2000، إلي نحو 8 ألف فدان عام 2014، بمقدار

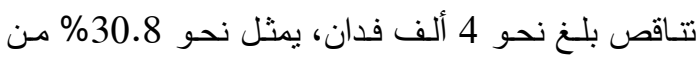
منوسط إجمالي مساحة البصل الصيفي خلال فترة الدراسة والبالغـة نحو 13 ألف فدان، في حين نزايـدت مسـاحة

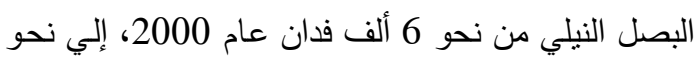

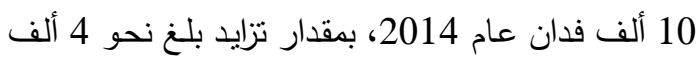
فدان، يمثل نحو 36.4\% مـن متوسط إجمالي مسـاحة البصل النيلي خـلال فترة الدراسـة والبالغة نحو 11 ألف

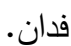

في حين نوضح نتائج جدول (2) معادلات الإتجاه الزمني العام لنطور المؤشرات الإنتاجية لمحصول البصل خلال فترة الدراسة، وكانت أفضل الصور المعبر عنها لهابل إحصائيا هي الصورة الموضحة قرين كل بيان للتعبير عن

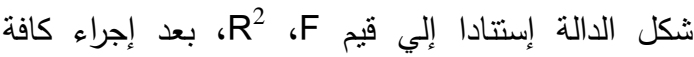
التحليلات الإحصائية لكل الصور الرياضية للتنغيرات موضع الدراسة. وقد تبين من نتائج الجدول أنه بالنسبة لتطور إجمالي مساحة البصل، مساحة البصل الثنوي، قد

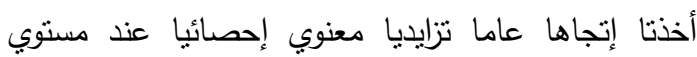

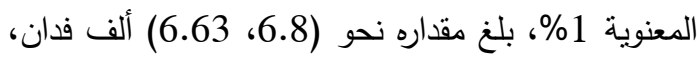
وبمعدل تغير بلغ نحو (5.44\%، 6.54\%) سنويا من متوسط المساحة المنزرعة بالبصل من كلا منهما والبالغة نحو (125.3، 101) ألف فدان علي الترتيب. في حين

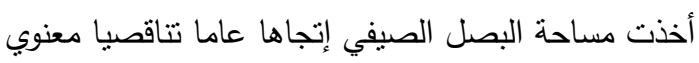
إحصائيا عند مستوي المعنوية 5\%، بلغ مقداره نحو 0.424 ألف فدان، وبمعدل تغير بلغ نحو 3.26\% سنويا من منوسط المساحة المنزرعة بالبصل الصيفي والبالغة نحو 13 ألف فدان. ويبين معامل التحديد أن نحو 82\% باليطول 81\%، 44\% من التغيرات الحادثة في المساحة المنزرعة
(الإيـراد الإقتصـادي - تكلفـة مسـتلزمات الإنتـاج بـدون الموارد المحلية إقتصاديا).

فإذا إنخفض هذا المعامل عن الواحد الصحيح دل ذلك

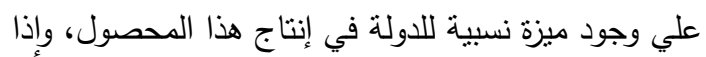
زاد المعامل عن الواحد يكون العكس (5، 6، 7).

وقد نم إستخدام السعر المجتمي أو سعر الحدود كما يلي: -سـعر الحـود أو السـعر المجتمعي لسـلعة صـادرات=

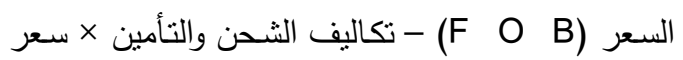
الصرف - (تكاليف النقل من الميناء إلى المصنع 3.6) + تكاليف التعبئة والنقل من المصنع للمزرعة 3.2٪).

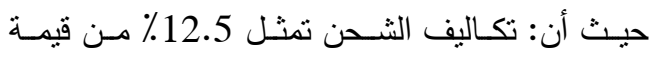

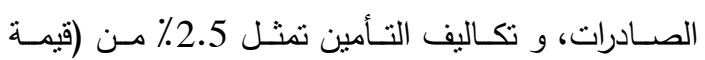
الصادرات + تكاليف الشحن). ويتم إجراء التقييم الإقتصـادي للإيراد الفداني استتادا

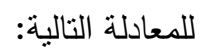
- التقيـيم الإقتصـــادي للإيـراد الفـداني= منوسـط الإنتـاج

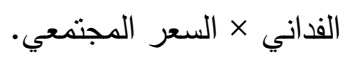

\section{النتائج ومناقشتها}

أولا: المؤثرات الإنتاجية لمحصول البصل

$$
\text { 1- تطور المساحة }
$$

يعتبر دراسـة الوضـع الإنتاجي لمحصول البصل من المن الأهمية بمكان حيث يعطي مؤشرات أولية عن مدي نطوره

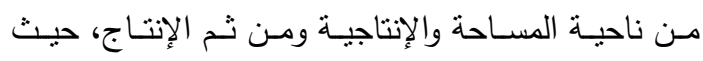
توضـح بيانات جدول (1) تطور مساحة محصول البصل في مصـر وفق معطيـات التسلسل الزمنـي خـلال الفتـرة (2000- 2014)، ومنه يتبين أن إجمالي المساحة الكلية قد تزايدت من نحو 91 ألف فدان عام 2000، إلي نحو إندالي

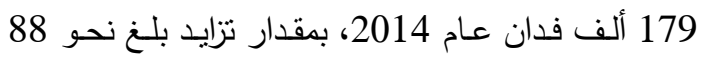
ألف فدان، يمثل نحو 70.4\% من منوسط إجمالي مساحة البصل خلال فترة الدراسة والبالغة نحو 125 ألف فدان، كما تزايدت مساحة البصل الثنتوي من نحو 73 ألف فدان عـام 2000، إلـي نــو 161 ألـف فـدان عـام 2014، 
طن/ فدان عام 2014، بمقدار زيادة بلغت نحو 3.5 طن/ فدان، يمثل نحو 25.62\% من منوسط الإنتاجية

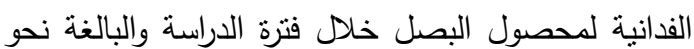
1213.66 طن/ فدان، ما ترتب عليه من زيادة في الإنتاج الكلي من البصل من نحو 1051.2 ألف طن عام

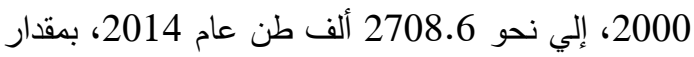
زيادة بلغت نحو 1657.4 ألف فدان، تمثل نحو 107.2 من متوسط إجمالي إنتاج البصل خلال فنرة الدراسة والبالغ نحو 1708.3 ألف طن.
بمحصول البصل لكل منهم علي الترتبب تعزي إلى

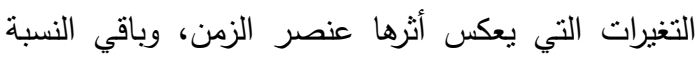
ترجع إلي عوامل أخري غير مقيسة بالدالة، في حين تبين عدم معنوية نطور الإتجاه العام لمساحة البصل النيلي. 2- 2 - 2 تطور الإنتاجية والإنتاج توضح بيانات جدول (1) نطور إنتاجية محصول البصل في مصر وفق معطبات التسلسل الزمني خلال فترة الدراسة، و تبين منه أن إنتاجية محصول البصل قد تزايدت من نحو 11.6 طن/ فدان عام 2000، إلي نحو 15.1

جدول (1): تطور المؤثرات الإتتاجية لمحصول البصل في مصر وفق معطيات التسلسل الزمني خلال الفترة (2000(المساحة ألف فدان، الإنتاجية بالطن، الإنتاج بالألف طن). .2014

\begin{tabular}{|c|c|c|c|c|c|c|}
\hline ألف طن & الإنتاجية طن/ & مساحة النيلي & مساحة الصبفي & مساحة الثتوي & إجمالي المساحة & السنوات \\
\hline 1051.2 & 11.55 & 6 & 12 & 73 & 91 & 2000 \\
\hline 1012.1 & 11.91 & 10 & 14 & 61 & 85 & 2001 \\
\hline 1097.3 & 11.93 & 10 & 12 & 70 & 92 & 2002 \\
\hline 1011.0 & 12.64 & 9 & 10 & 61 & 80 & 2003 \\
\hline 1327.7 & 13.15 & 11 & 15 & 75 & 101 & 2004 \\
\hline 1633.0 & 12.96 & 6 & 11 & 109 & 126 & 2005 \\
\hline 1195.6 & 12.86 & 10 & 18 & 65 & 93 & 2006 \\
\hline 1574.4 & 13.46 & 15 & 15 & 87 & 117 & 2007 \\
\hline 1886.3 & 13.87 & 12 & 15 & 109 & 136 & 2008 \\
\hline 2094.9 & 13.69 & 13 & 17 & 123 & 153 & 2009 \\
\hline 2310.1 & 13.92 & 13 & 19 & 134 & 166 & 2010 \\
\hline 2349.0 & 14.32 & 17 & 15 & 132 & 164 & 2011 \\
\hline 2202.6 & 14.40 & 9 & 8 & 136 & 153 & 2012 \\
\hline 2171.2 & 15.08 & 12 & 8 & 124 & 144 & 2013 \\
\hline 2708.6 & 15.13 & 10 & 8 & 161 & 179 & 2014 \\
\hline 1708.3 & 12.62 & 10.87 & 13.13 & 101.3 & 125.3 & المتوسط \\
\hline
\end{tabular}

المصدر: جمعت وحسبت من وزارة الزراعة وإستصلاح الأراضي، الإدارة المركزية للإقتصاد الزراعي، قطاع الثئون الإقتصادية، نشرة الإحصاءات الزراعية، أعداد مختلفة. 
(143.4\%، 148\%، 98.3\%، 56.3\%)، في حين إنخفتت نكلفة العمل الحيواني من نحو 5.6 جنيد/ فدان عام 2000، إلي أن إنعدمت عام 2014. في حين توضح نتائج جدول (4) معادلات الإتجاه الزمني العام لتطور كل من (تكلفة العمل البشري، تكلفة العمل الآلي، نكلفة المصروفات العمومية، الإيجار) للفدان

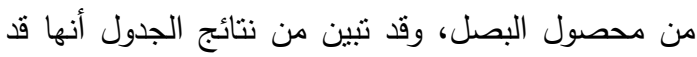
أخذت إتجاها عاما تزايديا معنوي إحصائيا عند مستوي

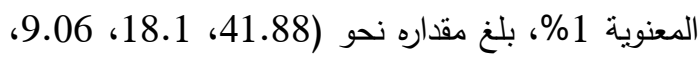
30.23) جنيها/ فدان، وبمعدل تغير بلغ نحو (6.1\%)،

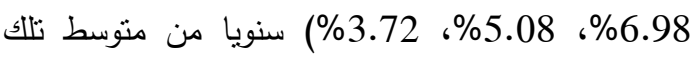
المتغيرات خلال فتزة الدراسة والبالغة نحو (686.4،

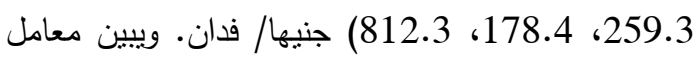

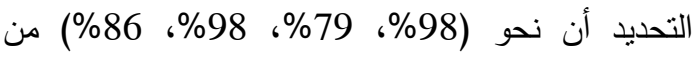

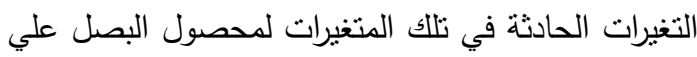
الترتيب تعزي إلي التغيرات التي يعكس أثرها عنصر

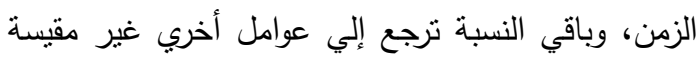

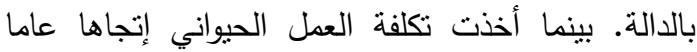

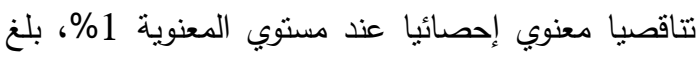

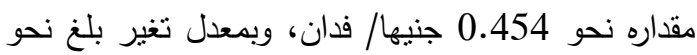
12.5 من منوسط تكلفة العطل الحيواني خلال فنرة الدراسة والبالغ نحو 3.63 جنيها/ فدان، ويبين معامل فيط نان التحديد أن نحو 54\% من التغيرات الحادثة في تكلفة العمل الحيواني لمحصول البصل تعزي إلي التغيرات التي

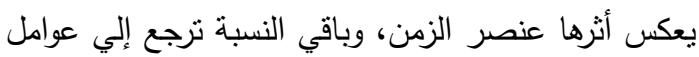

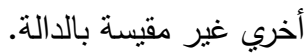

في حين توضح نتائج جدول (2) معادلات الإتجاه الزمني العام لنطور إنتاجية وإنتاج محصول البصل. وقد

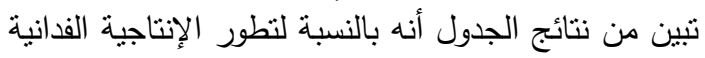
لمحصول البصل، الإنتاج أنهما قد أخذا إتجاها عاما لتاليا

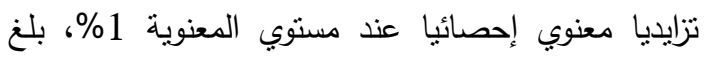

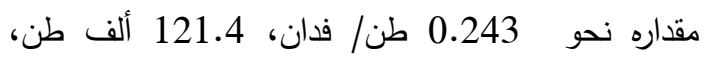
وبمعدل تغير بلغ نحو 1.87\%، 7.11 ألف طن سنويا من منوسط إنتاجية الفدان خلال فترة الدراسة، وكنلك

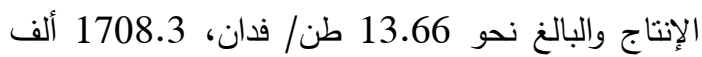

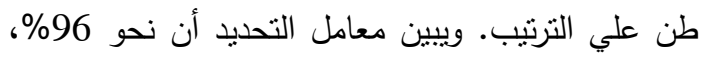
89 من التغيرات الحادثة في الإنتاجية الفدانية والإنتاج

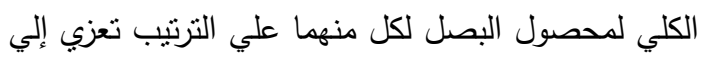

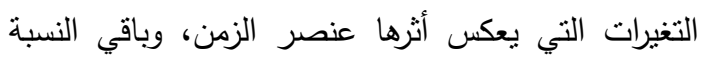
ترجع إلي عوامل أخري غير مقيسة بالدالة.

\section{ثانيا: المؤثرات الإقتصادية}

\section{1- تطور المؤثرات الإقتصادية مزرعيا}

تثشير بيانات جدول (3) إلي تطور تكاليف إنتاج محصول البصل في مصر مقيمة بالأسعار المزرعية خلال الفترة (2000- 2014)، ومنه يتبين أنه بالنسبة لنكلفة الموارد المحلية والتي شملت (تكلفة العمل البشري، تكلفة بلهة

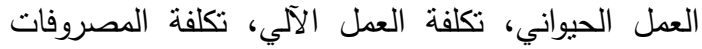

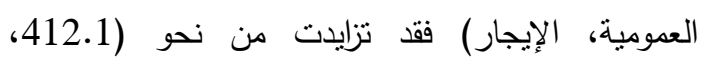
186.7، 127.1، 667.8) جنيها/ فدان عام 2000 إلي نداني نحو (1003، 454، 252، 1864، 1044) جنيها/ فدان خلال عام 2014، وبمقدار زيادة بلغت نحو (5724.9 (590.9، 276.3، 124.9، 376.2) جنيها/ فدان، وبنسبة مئوية قدرت بنحو نوك

جدول (2): معادلات الإتجاه الزمني العام لتطور المؤثرات الإنتاجية لمحصول البصل في مصر وفق معطيات التسلسل الزمني خلال الفترة (2000- 2014).

\begin{tabular}{|c|c|c|c|c|c|c|c|c|}
\hline $\begin{array}{c}\text { Change } \\
\text { ratio }\end{array}$ & $\begin{array}{c}\text { Change } \\
\text { value }\end{array}$ & Mean & $\mathrm{F}$ & $\mathrm{R}^{2}$ & $T$ & B & $\begin{array}{c}\text { Type } \\
\text { function }\end{array}$ & المتغير \\
\hline 5.44 & 6.8 & 125.3 & 60.75 & 0.82 & 8.95 & 6.8 & خطية & إجمالي المساحة \\
\hline 6.54 & 6.63 & 101 & 56.9 & 0.81 & 7.55 & 6.63 & خطية & مساحة الثتوي \\
\hline-3.26 & -0.424 & 13 & 4.74 & 0.44 & $\begin{array}{c}2.67 \\
-2.95 \\
\end{array}$ & $\begin{array}{c}1.99 \\
-0.134 \\
\end{array}$ & تربيعية & مساحة الصيفي \\
\hline 1.87 & 0.243 & 13.66 & 312 & 0.96 & 17.7 & 0.243 & خطية & الإنتاجية \\
\hline 7.11 & 121.4 & 1708 & 108.9 & 0.89 & 10.4 & 121.4 & خطبة & الإنتاج \\
\hline
\end{tabular}

المصدر: جمعت وحسبت من بيانات جدول (1). 


\begin{tabular}{|c|c|c|c|c|c|c|c|c|c|c|c|c|c|c|c|c|c|}
\hline \multicolumn{2}{|l|}{ 手 } & চి & ठิ & ઠิ & ชి & ఫั. & '气े & ठั. & Бे & 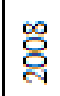 & ิㅗㅁ & 옳 & 코ำ & ్ㅗㅀำ & ติ่ & 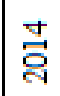 & 高 \\
\hline \multirow{5}{*}{ 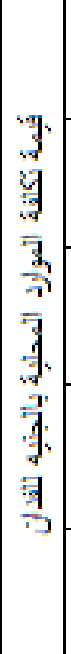 } & “零 & ت゙્ & 导 & 范 & g & 至 & gू & \% & 告 & $\stackrel{\Re}{q}$ & $\vec{E}$ & ฉี & 2 & $\vec{\infty}$ & $\begin{array}{l}\infty \\
\stackrel{\circ}{\circ}\end{array}$ & \% & 登 \\
\hline & “否管 & مْ مُ & 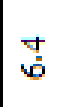 & 'َ & in & in & in & $\bullet$ & in & r & 0 & 0 & 0 & 0 & 0 & 0 & గ్రి \\
\hline & & 㤐 & 䉥 & $\begin{array}{l}9 \\
0 \\
\stackrel{0}{=}\end{array}$ & $\stackrel{\circ}{\circ}$ & 욤 & 옥 & 売 & 羔 & ฮี & 等 & ब্ণ & 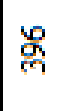 & 点 & से & 売 & वे \\
\hline & 等尔 & 穿 & 等 & ัำ & 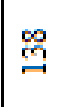 & 兴 & 5 & $\stackrel{8}{\circ}$ & $\stackrel{ \pm}{\Xi}$ & హี & $\stackrel{2}{\mathrm{a}}$ & ఫે & สి & $\stackrel{\infty}{\sim}$ & สี & ชี & 愈 \\
\hline & & $\stackrel{\infty}{6}$ & 嗬 & ํㅜㅇ & ঃ & 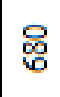 & 연 & 吉 & 2 & $\stackrel{2}{2}$ & สั & $\overrightarrow{\mathrm{g}}$ & $\check{\swarrow}$ & 合 & 옴 & 导 & 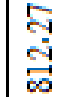 \\
\hline \multirow{4}{*}{ 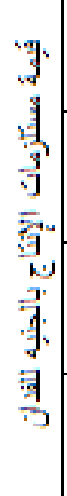 } & & $\frac{9}{5}$ & 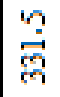 & $\begin{array}{l}0 \\
\text { o̊ } \\
\text { ơ }\end{array}$ & యี & 号 & 훙 & 荋 & 集 & 多 & 㝵 & 䧽 & గี & $\overline{8}$ & 굠 & \%ู & 告 \\
\hline & 青 寻 & gิ & 量 & $\overrightarrow{\text { ڤ̇ }}$ & $\vec{n}$ & 6 & $尺$ & $\mathbb{F}$ & $\stackrel{2}{\gtrless}$ & ऽ & $\stackrel{2}{\circ}$ & ને & $n$ & 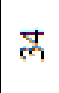 & 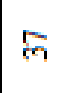 & 2 & 筞 \\
\hline & $\frac{3}{3}$ & लํ. & ํㅗㅇ & ปे & 옹 & ' & 弄 & 登 & 丞 & ঙั & gू & $\stackrel{0}{\sim}$ & สี & 夺 & 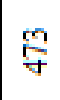 & \%ี & 苞 \\
\hline & 苛泰 & 每 & 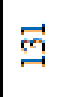 & 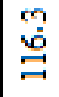 & 气 & $\stackrel{\infty}{=}$ & $\vec{\exists}$ & 옥 & 学 & శู & 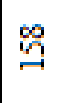 & $\stackrel{8}{\circ}$ & $E$ & 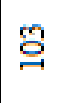 & 옴 & 吕 & 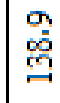 \\
\hline \multirow{5}{*}{ 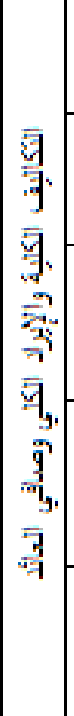 } & 司牙 & đั่ & 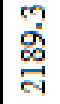 & 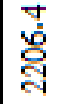 & 음 & 芯 & ช్ & 点 & స్ & 울 & & 学 & న్ల & 点 & 魚 & 多 & ज्ञ \\
\hline & 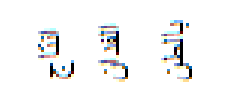 & 弇 & $\stackrel{a}{g}$ & $\stackrel{\text { g }}{\stackrel{\Xi}{=}}$ & 志 & 告 & $\begin{array}{l}\mathscr{2} \\
\text { త్ }\end{array}$ & 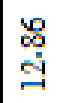 & 早 & 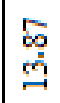 & 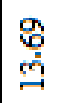 & ๙ิ & ชู & 导 & 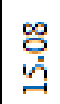 & 学 & 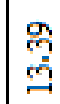 \\
\hline & 可勇等 & 管 & สี่ & ปี & 옴 & 올 & 吕 & 웅 & 웅 & 웅 & 웅 & 옹 & 웅 & 옹 & 号 & 웅 & 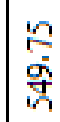 \\
\hline & 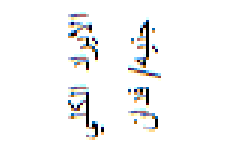 & 움 & 웅 & 学 & 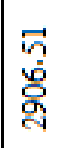 & $\begin{array}{l}\text { gे } \\
\text { ờ } \\
\text { 户 }\end{array}$ & 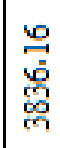 & 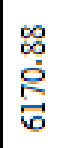 & 点 & लु & 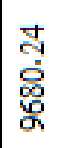 & 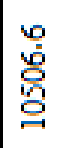 & 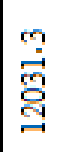 & 品 & लू & 号 & 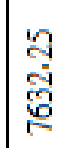 \\
\hline & 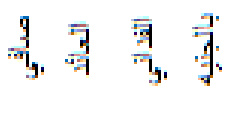 & 官 & 总 & $\stackrel{\frac{9}{\sigma}}{\stackrel{\vec{\sigma}}{n}}$ & 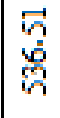 & 웅 & 궁 & న్ & 웅 & 尔 & ণู & $\begin{array}{l}0 \\
\circ 0 \\
\varnothing 0\end{array}$ & 唀 & 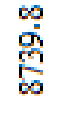 & 莳 & สิ & 공 \\
\hline
\end{tabular}


H. M. M. Seddik

جلول (4): معالم معادلات الإتجاه الزمني العام لتطور المؤثرات الإقتصادية لمحصول البصل في مصر وفق معطيات التسلسل الزمني خلال الفترة (2000- 2014).

\begin{tabular}{|c|c|c|c|c|c|c|c|c|c|}
\hline $\begin{array}{c}\text { Change } \\
\text { ratio }\end{array}$ & $\begin{array}{c}\text { Change } \\
\text { value }\end{array}$ & Mean & $\mathrm{F}$ & $\mathrm{R}^{2}$ & $\mathrm{~T}$ & B & $\begin{array}{c}\text { Type } \\
\text { function }\end{array}$ & $\begin{array}{l}\text { number } \\
\text { function }\end{array}$ & المتغير التابع \\
\hline 6.101 & 41.875 & 686.39 & 642.8 & 0.980 & 25.354 & 41.875 & Liner & 1 & البشري \\
\hline-12.5 & -0.4540 & 3.633 & 15.04 & 0.536 & -3.879 & -0.454 & Liner & 2 & ت الحيوانية \\
\hline 6.981 & 18.098 & 259.25 & 48.33 & 0.788 & 6.9520 & 18.098 & Liner & 3 & تكلفة العمل الآلي \\
\hline 5.08 & 9.0620 & 178.37 & 681.7 & 0.981 & 26.108 & 9.062 & Liner & 4 & تكلفة المصرووفات \\
\hline 3.721 & 30.226 & 812.27 & 81.92 & 0.863 & 9.051 & 30.226 & Liner & 5 & تكلفة الإيجار \\
\hline 3.386 & 15.831 & 467.53 & 89.53 & 0.873 & 9.462 & 15.831 & Liner & 6 & تكلفة التقاوي \\
\hline 5.987 & 21.936 & 366.4 & 66.72 & 0.837 & 8.168 & 21.936 & Liner & 8 & ت تكلفة $\quad$ الكيماوب $\quad$ السماد \\
\hline 4.707 & 139.89 & 2972.1 & 546.2 & 0.98 & 23.37 & 139.89 & Liner & 10 & التكاليف الكلية \\
\hline 11.06 & 60.790 & 549.8 & 283.7 & 0.96 & 16.84 & 60.790 & Liner & 11 & السعر المزرعي \\
\hline 12.44 & 949.10 & 7632.3 & 365.2 & 0.97 & 19.1 & 949.10 & Liner & 12 & الإيراد الكلي \\
\hline 17.37 & 809.30 & 4660.1 & 300.8 & 0.96 & 17.43 & 809.30 & Liner & 13 & صافي العائد \\
\hline
\end{tabular}

المصدر : جمعت وحسبت من بيانات جدول (3).

التغيرات التي بعكس أثزها عنصر الزمن، وباقي النسبة ترجع إلي عوامل أخري غير مقيسة بالدالة. بينما كانت

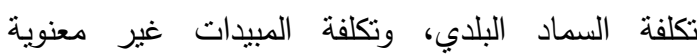
إحصائيا.

كما يين جدول (3) أيضا أنه بالنسبة لكل من (إجمالي التكاليف، السعر المزرعي، إجمالي الإيراد، صافي العائد)

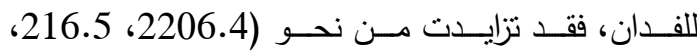

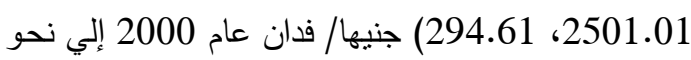

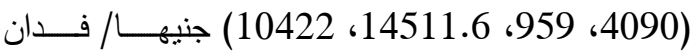
خلال عام 2014، وبمقدار زيادة بلغت نحو (1883.6،

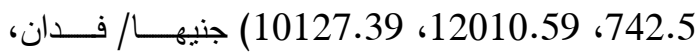

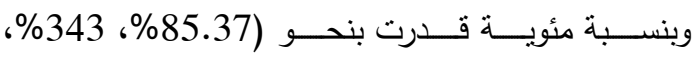
. $\% 3437.6$ \% \% 480.2 في حين نوضح نتائج جدول (4) معادلات الإتجاه الزمني العام لنطور كل من (التكاليف الكلية، السعر المزرعي، الإيراد الكلي، صافي العائد) للفدان من محصول

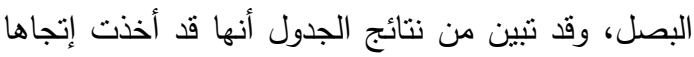

كمـا تبـين مـن جدول (3) أيضـا أنـه بالنسبة لتطور تكاليف مستلزمات الإنتاج والتي شملت تكلفة (التقاوي، السماد الكيماوي، المبيدات) فقد تزايدت من نحو (397.9،

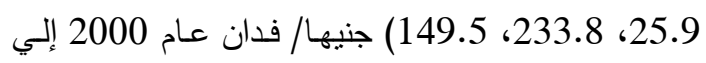

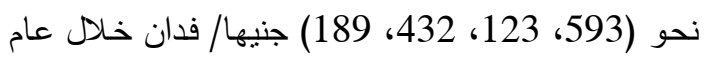
2014، وبمقــار زيــادة بلغـت نحسو (195.1، 97.1، 198.2، 39.5) جنيها/ فدان، وبنسبة مئوية قدرت بنحو .\%26.42، \%44.8، \%374.93) في حين توضح نتائج جدول (4) معادلات الإتجاه الزمني العام لتطور تكلفة (التقاوي، السماد الكيماوي) للفدان من محصول البصل، وقد تبين من نتائج الجدول أنها قد أخذت إتجاها عاما تزايديا معنوي إحصائيا عند مستوي المعنوية 1\%، بلغ مقداره نحو (15.83،

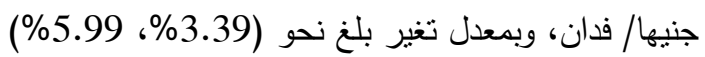
سنويا من متوسط تلك المتغيرات خلال فترة الدراسة والبالغة

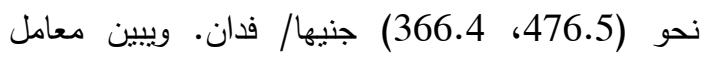
التحديد أن نحو (87\%، 84\%) من التغيرات الحادثة في تلكك المتغيرات لدحصول البصل علي الترتيب تعزي إلي 
2- تطور المؤثرات الإنتاجية ماليا واقتصاديا توضح البيانات الواردة بجدول (5) متوسط المؤشرات الإنتاجية لمحصول البصل ماليا وإقتصاديا، كمنوسط للفترة (2000- 2014)، وقد تبين أنـه بالنسبة للمؤشرات ماليا والتي شملت كل من (إجمالي قيمة تكلفة الموارد المحلية،

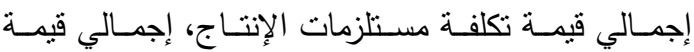
التكاليف الكلية، إجمالي الإيرادات، متوسط صافي العائد)، فقد بلغت حوالي (1.94، 1.03، 2.97، 7.63، 7.63 (4.66) ألف جنيه علي الترتيب. كما بلغت قيمة تلك المؤشرات إقتصـاديا حوالي (2.23، 1.12، 3.35، 21.1، 17.7) ألف جنيه علي النرتيب.
عاما تزايديا معنوي إحصائيا عند مسنوي المعنوية 13\%، بلغ مقداره نحو (139.9، 60.8، 949.1، 809.3)

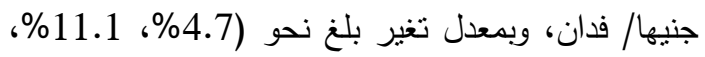
12.4\%، 17.4\%) سنويا من متوسط تلك المتغيرات خلال فترة الدراسة والبالغة نحو (2972.1، 549.8، 7632.3، 4660.1) جنيها/ فدان. وبيين معامل التحديد

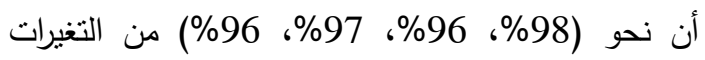
الحادثة في تلك المتغيرات لمحصول البصل علي الترتيب

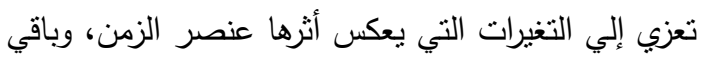
النسبة ترجع إلي عوامل أخري غير مقيسة بالدالة.

جدول (5): مؤثـرات تكاليف وإيرادات وصـافي عائد النـاتج الفداني لمحصول البصل ماليـا وإقتصـاديا كمتوسط للفترة .2014-2000)

\begin{tabular}{|c|c|c|}
\hline التقييم الإقتصادي & التقييم المالي & ل البيان \\
\hline \multicolumn{3}{|r|}{ ؤلا: قيمة التكاليف } \\
\hline & & أ- تكلفة الموارد المحلية \\
\hline 459.88 & 686.39 & أجور عمال غير مناجر \\
\hline 3.6333 & 3.6333 & أجور حيوانات غير متاجر \\
\hline 388.88 & 129.63 & أجور آلات متاجر \\
\hline 388.88 & 129.63 & أجور آلات غير متاجر \\
\hline 89.180 & 89.187 & مصاريف عمومية متاجر \\
\hline 89.180 & 89.187 & مصاريف عمومية غير متاجر \\
\hline 812.30 & 812.27 & إيجار غير متاجر \\
\hline 2231.93 & 1939.93 & إجمالي قيمة تكلفة الموارد المحلية \\
\hline \multicolumn{3}{|r|}{ ب- تكلفة مستلزمات الإنتاج } \\
\hline 490.91 & 467.53 & تقاوي مناجر \\
\hline 59.430 & 59.430 & سماد بلدي غير متاجر \\
\hline 403.04 & 366.40 & سماد كيماوي متاجر \\
\hline 166.60 & 138.90 & مبيدات متاجر \\
\hline 1119.98 & 1032.26 & إجمالي قيمة تكلفة مستلزمات الإنتاج \\
\hline 3351.92 & 2972.1 & إجمالي قيمة التكاليف الكلية \\
\hline \multicolumn{3}{|r|}{ ثانيا: قيمة الإيرادات } \\
\hline 1494.63 & 549.75 & متوسط سعر الطن \\
\hline 12.620 & 12.620 & متوسط الإنتاجية \\
\hline 21098.9 & 7632.2 & إجمالي إيرادات الفدان \\
\hline 17746.99 & 4660.1 & متوسط صافي العائد \\
\hline
\end{tabular}

المصدر: جمعت وحسبت من جداول (1، 3، 4). 
من منوسط تلك المتغيرات علي التزتيب خلال الفترة سالفة الذكر ـ كما تبين بيانات نفس الجدول معادلات الإتجاه الزمني العام لتطور تلك المؤشرات إقتصاديا وكانت أيضا لأنسا

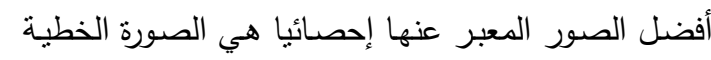

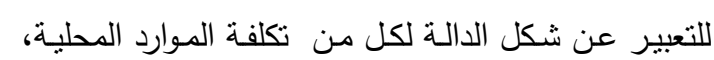

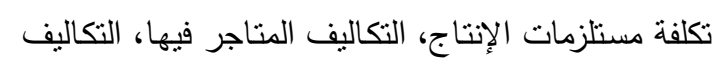
الغير متاجر فيها، الإيراد الكلي، وقد كانت جميعها متزايدة

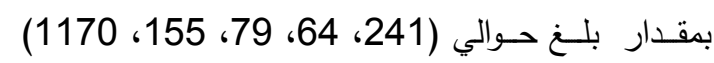

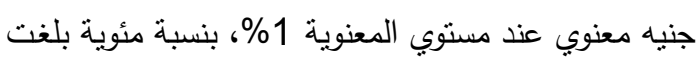

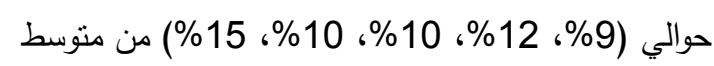
متغيرات الدراسة لكل منهم علي النتريب خلال الفترة بالغة 10،

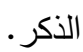

في حين توضـح النتائج الواردة بجدول (6) معادلات

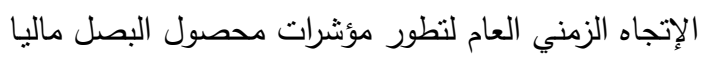
وإقتصاديا، خلال الفترة (2000- 2014)، وكانت أفضل لفرل الصور المعبر عنها إحصائيا هي الصورة الخطية للتعبير

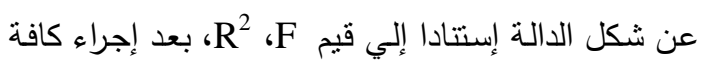

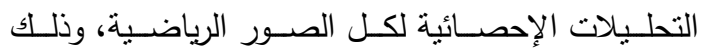
للمؤشرات ماليا والتي شملت (تكلفة الموارد المحلية، تكلفة مستلزمات الإنتاج، التكاليف المتاجر فيها، التكاليف الغير

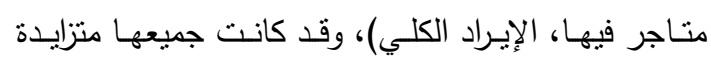

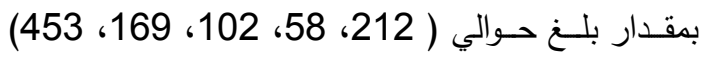

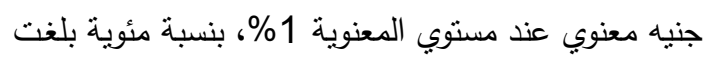

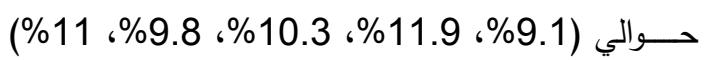

جدول (6): معادلات الإتجاه الزمني العام لتطور المؤثرات الإقتصادية ماليا وإقتصاديا لمحصول البصل وفق معطيات التسلسل الزمني خلال الفترة (2000- 2014).

\begin{tabular}{|c|c|c|c|c|c|c|c|c|}
\hline $\begin{array}{c}\text { Change } \\
\text { rate }\end{array}$ & $\begin{array}{c}\text { Change } \\
\text { value }\end{array}$ & Mean & $\mathrm{F}$ & $\mathrm{R}^{2}$ & $\mathrm{~T}$ & B & 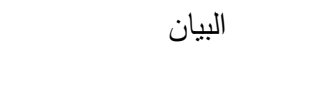 & \\
\hline 5.093 & 98.80 & 1939.9 & 629.7 & 0.99 & $\begin{array}{l}2.42 \\
5.91\end{array}$ & $\begin{array}{l}29.28 \\
4.345\end{array}$ & الموارد المحلية & \multirow{5}{*}{$\begin{array}{l}\overline{7} \\
\overline{3} \\
\overline{3} \\
\overline{3} \\
\overline{3}\end{array}$} \\
\hline 3.98 & 41.081 & 1032.21 & 178.7 & 0.93 & 13.37 & 41.081 & مستلزمات الإنتاج (خطية) & \\
\hline 4.463 & 53.18 & 1191.6 & 211.4 & 0.94 & 14.54 & 53.18 & تكاليف متاجر فيها (خطية) & \\
\hline 4.869 & 86.71 & 1780.54 & 437.7 & 0.99 & $\begin{array}{l}2.93 \\
4.02 \\
\end{array}$ & $\begin{array}{l}37.16 \\
3.097 \\
\end{array}$ & تكاليف غير متاجر فيها & \\
\hline 12.44 & 949.1 & 7632.25 & 365.2 & 0.97 & 19.1 & 949.1 & الإيراد الكلي (خطية) & \\
\hline 5.429 & 121.18 & 2231.92 & 144.85 & 0.92 & 12.04 & 121.18 & الموارد المحلية & \multirow{5}{*}{ 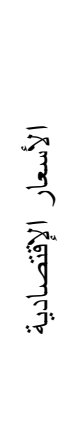 } \\
\hline 3.967 & 44.43 & 1120 & 162.4 & 0.93 & 12.74 & 44.43 & مستلزمات الإنتاج (خطية) & \\
\hline 4.85 & 74.63 & 1538.64 & 170.6 & 0.93 & 13.06 & 74.63 & تكاليف متاجر فيها (خطية) & \\
\hline 5.018 & 90.99 & 1813.28 & 216.05 & 0.94 & 14.7 & 90.99 & تكاليف غير متاجر فيها & \\
\hline 16.99 & 3584.6 & 21098.9 & 95.91 & 0.88 & 9.79 & 3584.6 & الإيراد الكلي (خطية) & \\
\hline
\end{tabular}

* معنوي عند مستوي المعنوية 5\%، فيما عدا ذلك معنوي عند مستوي المعنوية 1\%.

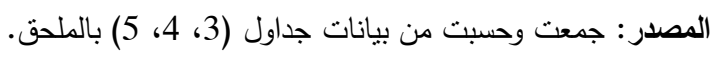


الإنتاج ومستلزماته علي حد سواء، لذا فهو معيار أكثر كفاءة لبيان أثر السياسة الإقتصادية المحلية علي أسواق

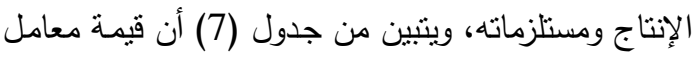
الحماية الفعال لمحصول البصل خلال فترة الدراسة كانت

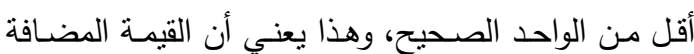

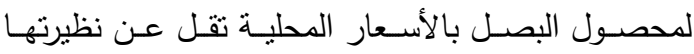

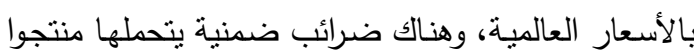

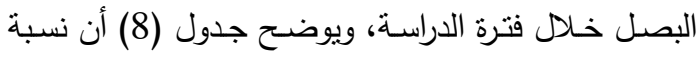
هذه الضرائب تراوحت ما بين حد أدني بلغ نحو 27.3 بقيمة تقدر بنحو 1969.9 جنيها للفدان عام 2006، وحدان أقصسي بلـغ نحو 77.7\% بقيمـة تقدمر بنحو 41956.3 جنيها للفدان عام 2013، في حين بلغ متوسط نسبة الفترة حسوالي 55.7\% بقيمـة بلغـتـ نحسو 13402.1 جنيهـا

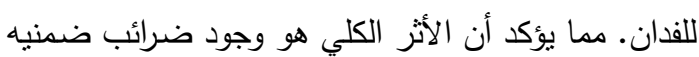

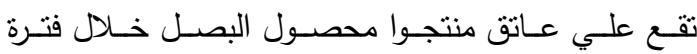
الدراسة.

سادسـا - معامـل تكلفــة المـوارد المحليـة (الميزة (النسبية) (DRC)

يعكس هـذا المعامـل مفهوم كفـاءة الإنتـاج المحلـي بالنسبة للسوق العالمي، ويبين مدي قدرة الدولة علي إحلال

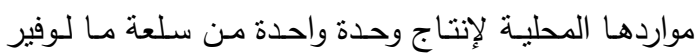

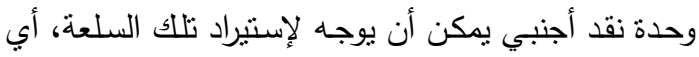

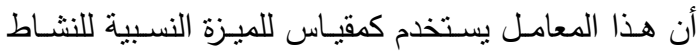
الإنتاجي، وتثتير النتائج الواردة بجدول (7) إلي أن معامل

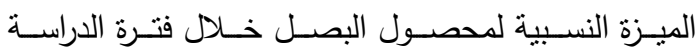
(2000- 2014) كان أقل من الواحد الصحيح، ما يؤكد

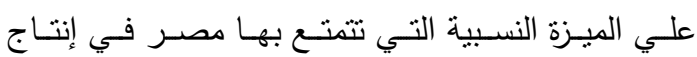
الدحصول نتيجة إنخفاض تكلفة إنتاجه محليا عن تكلفة إستنيراده، وبـالرغم مـن إرتفاع قيمـة المعامل عام 2000

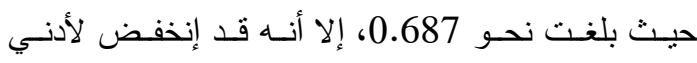

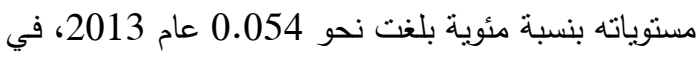
حين بلغ منوسط الفترة نحو 0.238، وهذا بعني أنه يلزم

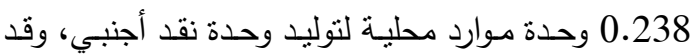

كمـا توضــح نتـائج نفس الجـدول معـادلات الإتجـاه الزمني العام لتطور تلك المؤشرات إقتصاديا والتي شملت (تكلفة الموارد المحلية، تكلفة مستلزمات الإنتاج، التكاليف المتاجر فيها، التكاليف غير المتاجر فيها، والإيراد الكلي)،

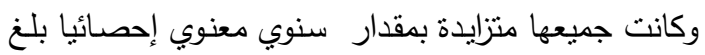

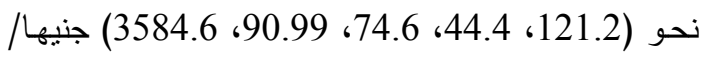

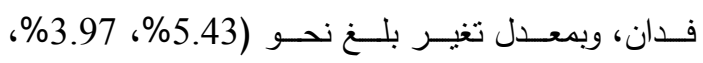
4.85\%، 5.02\%، 16.99\%) من منوسط نلك المتغيرات

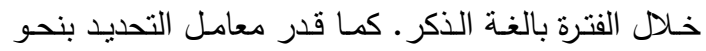

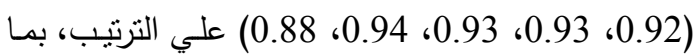
يفسر التغيرات الحادثة في تلك المتغيرات بنفس النسبة النس

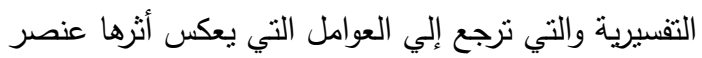
الزمن، وذلك خلال نفس الفترة الزمنية سابقة الذكر .

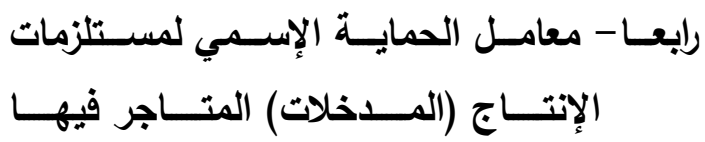

(NPCl)

توضح النتائج الواردة بجدول (7) أن معامل الحمايـة الإســي لمستلزمات الإنتـاج (المــخلات) المتــاجر فيهـا لمحصول البصل خلال فترة الدراسة كانت قيمته أقل من الإن الإن

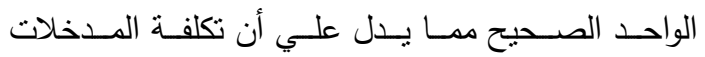
بالأسعار المحلية أقل من نظيرتها بسعر الحدود وإن كانت

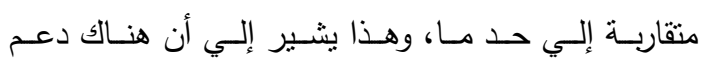

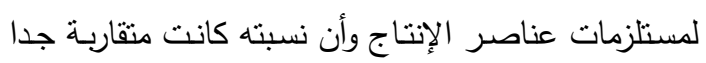

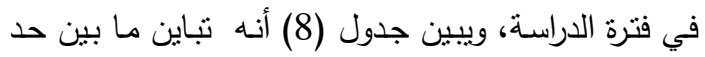

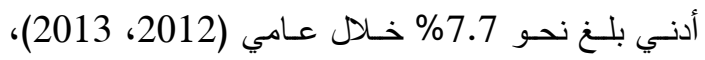
وبقيمـة نقديـة بلغت نحـو (93.9، 97.2) جنيهـا للفـدان

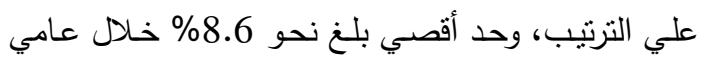
(2000، 2010)، وبقيمــة نقديـة بلغــت نحـــ 73.5، 108.5 جنيها للفدان علي الترتيب، بمتوسط للفترة بلغت نسبته نحو 8.3\% وبقيمة بلغت نحو 87.9 جنيها للفدان. خامسا- معامل الحماية الفعال (EPC) يشير هذا المعامل إلي النتوهات السعرية في أسواق 
منتجــوا محصـول البصـل، و يعـزي ذلـك إلـي الضــرائب

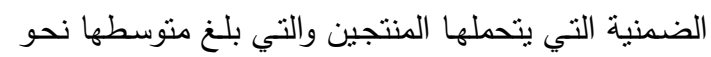

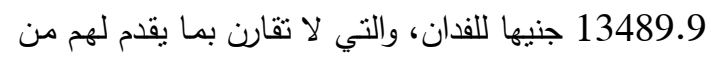
دعم والذي قدر متوسطه بنحو 87.9 جنيها للفدان خلال فترة الدراسة (2000- 2014).
تبين إرتفـاع الميزة النسبية في إنتـاج المحصـول نتيجـة إنخفاض معامل نكلفة الموارد المحلية من نحو 0.687 عام 2000 إلي نحو 0.079 عام 2014 بمعدل إنخفاض بلغ نحو 60.8\% مقارنة بعام 2000.

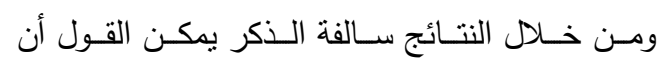
السياسات الزراعية التي تنتهجها الدولة لم تكن في صالح

جدول (7): تطور معاملات الحماية الإسمية والفعالية وتكلفة الموارد المحلية لمحصول البصل وفق معطيات التسلسل الزمني خلال الفترة (2000- 2014).

\begin{tabular}{|c|c|c|c|c|}
\hline تكلفة الموارد المحلية & معامل الحماية الفعال & للمستلزمات المتامر فيها الإسمي & معامل الحماية الإسمي & 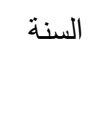 \\
\hline 0.687 & 0.715 & 0.914 & 0.77 & 2000 \\
\hline 0.539 & 0.628 & 0.913 & 0.68 & 2001 \\
\hline 0.51 & 0.611 & 0.919 & 0.67 & 2002 \\
\hline 0.274 & 0.331 & 0.919 & 0.4 & 2003 \\
\hline 0.264 & 0.486 & 0.918 & 0.54 & 2004 \\
\hline 0.310 & 0.475 & 0.917 & 0.53 & 2005 \\
\hline 0.280 & 0.727 & 0.917 & 0.75 & 2006 \\
\hline 0.164 & 0.599 & 0.917 & 0.62 & 2007 \\
\hline 0.078 & 0.299 & 0.916 & 0.32 & 2008 \\
\hline 0.075 & 0.271 & 0.915 & 0.29 & 2009 \\
\hline 0.087 & 0.315 & 0.914 & 0.34 & 2010 \\
\hline 0.091 & 0.337 & 0.915 & 0.36 & 2011 \\
\hline 0.081 & 0.311 & 0.923 & 0.33 & 2012 \\
\hline 0.054 & 0.223 & 0.923 & 0.24 & 2013 \\
\hline 0.079 & 0.314 & 0.916 & 0.33 & 2014 \\
\hline 0.238 & 0.443 & 0.917 & 0.48 & المتوسط \\
\hline
\end{tabular}

المصدر : جمعت وحسبت من بيانات جداول (3، 4، 5) بالملحق. 
جدول (8): تقدير قيمة الضرائب أو الاعم للقدان لمحصول البصل وقياس الميزة النسبية وفق معطيات التسلسل الزمني خلال الفترة (2000- 2014).

\begin{tabular}{|c|c|c|c|c|c|c|c|}
\hline \multirow{2}{*}{ النسبية } & \multicolumn{2}{|c|}{ في حالة معامل الدمم و الضرائب } & \multicolumn{2}{|c|}{ الدعم في حالة معامل الحماية } & \multicolumn{2}{|c|}{ الضرائب في حالة معامل } & /اليان \\
\hline & قيمة & $\%$ & قيمة & $\%$ & قيمة & $\%$ & \\
\hline$*$ & 676.592 & 0.285 & 73.4767 & 0.086 & 750.0691 & 0.23 & 2000 \\
\hline$*$ & 1185.08 & 0.372 & 63.5970 & 0.087 & 1248.678 & 0.32 & 2001 \\
\hline$*$ & 1269.13 & 0.389 & 66.4629 & 0.081 & 1335.596 & 0.33 & 2002 \\
\hline$*$ & 4268.55 & 0.669 & 70.3890 & 0.081 & 4338.942 & 0.6 & 2003 \\
\hline$*$ & 3481.49 & 0.514 & 73.3490 & 0.082 & 3554.834 & 0.46 & 2004 \\
\hline$*$ & 3305.08 & 0.525 & 78.5637 & 0.083 & 3383.643 & 0.47 & 2005 \\
\hline$*$ & 1969.92 & 0.273 & 84.5355 & 0.083 & 2054.458 & 0.25 & 2006 \\
\hline$*$ & 4850.34 & 0.401 & 86.5109 & 0.083 & 4936.846 & 0.38 & 2007 \\
\hline$*$ & 19073.8 & 0.701 & 98.0028 & 0.084 & 19171.78 & 0.68 & 2008 \\
\hline$*$ & 23346.6 & 0.729 & 98.4598 & 0.085 & 23445.05 & 0.71 & 2009 \\
\hline$*$ & 20351.9 & 0.685 & 108.515 & 0.086 & 20460.46 & 0.66 & 2010 \\
\hline$*$ & 21280.2 & 0.663 & 113.807 & 0.085 & 21394.05 & 0.64 & 2011 \\
\hline$*$ & 24880.2 & 0.689 & 93.8977 & 0.077 & 24974.05 & 0.67 & 2012 \\
\hline$*$ & 41956.3 & 0.777 & 97.1778 & 0.077 & 42053.46 & 0.76 & 2013 \\
\hline$*$ & 29135.6 & 0.686 & 111.271 & 0.084 & 29246.91 & 0.67 & 2014 \\
\hline$*$ & 13402.1 & 0.557 & 87.8676 & 0.083 & 13489.92 & 0.522 & المتوسط \\
\hline
\end{tabular}

* تثير إلي وجود ميزة نسبية في الإنتاج. المصدر : جمعت وحسبت من بيانات جداول (3، 4، 5) بالملحق.

(2) دعاء إسماعيل مرسي (دكتور) وآخرون، دراسة

لبعض المؤشرات الإنتاجية والتصديرية لمحصول

(1) السيد البدوي جمال (دكتور)، عفيفي علي عفيفي

البصل في مصر، المجلة المصرية للإقتصاد (دكتور)، إقتصاديات إنتاج البصل المصري والآثار

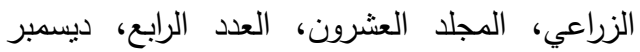

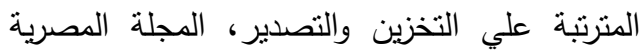


(6اني سعيد عبد الرحمن الشتلة (دكتور)، تحليل السياسات الزراعية لأهم محاصيل الحبوب الإسنيرادية

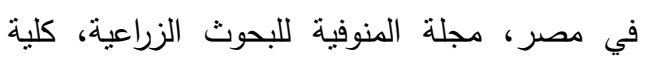
الزراعة، جامعة المنوفية، مجلد 38، العدد (1)،

$$
\text { الجزء الثاني، فبراير } 2013 .
$$

(7) هيدي علي حسن (دكتور)، أثز السياسة الزراعية علي

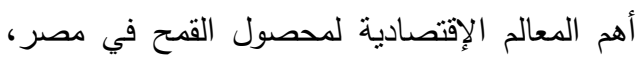

المجلة المصرية للإقتصاد الزراعي، المجلد العشرون،

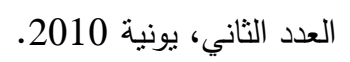

الجهاز المركزي للتعبئة العامة والإحصاء، نشرة

التجارة الخارجية، أعداد مختلفة.

(9) وزارة الزراعة وإسنصلاح الأراضي، قطاع الثئون

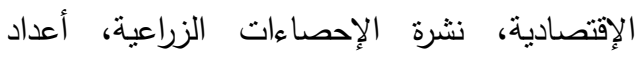

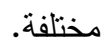

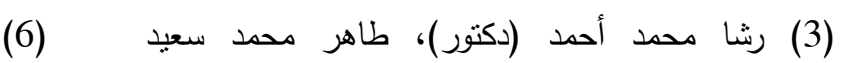

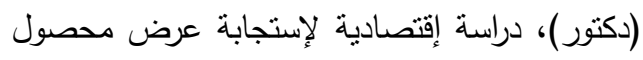
البصل في مصر، المجلة المصرية للإقتصاد

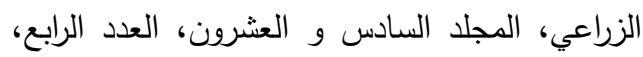
ديسمبر 2016. (4) عادل يوسف عوض (دكتور) وآخرون، تقييم أثنر سياسة النحرر الإقتصادي علي المتغيرات الإنتاجية وانية

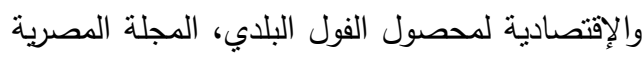

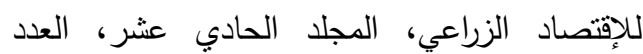
الأول، مارس 2001. (5) محمد سالم مشعل (دكتور) وآخرون، تحليل السياسات الزراعية لبعض محاصيل النباتات الطبية والعطرية ولئية

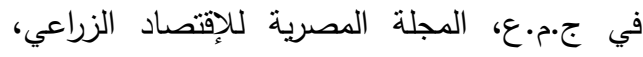
المجلد العشرون، العدد الثالث، سبتمبر 2010.

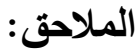

جدول (1): نسبة بنود عناصر الإنتاج المتاجر وغير المتاجر فيها للحاصلات الزراعية ومعاملات تحويل الأسعار المالية

\begin{tabular}{|c|c|c|c|c|}
\hline لأسعار إقتصادية بعد التحرر الأسعار المالية & لأسعار إقتصادية فبل التحرر الأسعار المالية & غير متاجر & فناجر & بند التكاليف \\
\hline 1.05 & 1.490 & 0.00 & 1.00 & التقاوي \\
\hline 1.10 & 1.663 & 0.00 & 1.00 & الأسمدة الكيماوية \\
\hline 0.00 & 0.000 & 1.00 & 0.00 & السماد البدي \\
\hline 1.20 & 1.976 & 0.00 & 1.00 & المبيدات \\
\hline 1.50 & 1.590 & 0.50 & 0.50 & الميكنة والآلات \\
\hline \multirow[t]{5}{*}{0.67} & 0.500 & 1.00 & 0.00 & العمالة \\
\hline & & 1.00 & 0.00 & العمل الحيواني \\
\hline & & 0.70 & 0.30 & مياه الري \\
\hline & & 1.00 & 0.00 & الإيجار \\
\hline & & 0.50 & 0.50 & مصروفات أخري \\
\hline
\end{tabular}
لأسعار إقتصادية قبل ويعد سياسة التحرر الإقتصادي.

Source; World Bank.The economics of project analysis.Washington d.c, 1991, p, 220. 
جلول (2): الأسعار المالية والإقتصادية لمحصول البصل بالجنيه للطن وفق معطيات التسلسل الزمني خلال الفترة .(2014-2000)

\begin{tabular}{|c|c|c|c|c|c|c|c|c|c|}
\hline الأو المزعبة & سأو السعر الحدود & اللقاليف & النقاليف & الثكاليف & تكاليف & تكاليف & 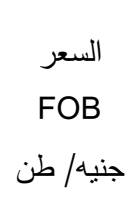 & مليون الصادرات & السنوات \\
\hline 216.5 & 282.3 & 1.380 & 1.553 & 6.6043 & 1.213 & 5.391 & 291.84 & 43.13 & 2000 \\
\hline 223.4 & 327.7 & 1.811 & 2.038 & 8.6669 & 1.592 & 7.075 & 340.23 & 56.60 & 2001 \\
\hline 228.4 & 339.3 & 3.407 & 3.833 & 16.305 & 2.995 & 13.31 & 362.88 & 106.48 & 2002 \\
\hline 230.0 & 572.3 & 6.311 & 7.100 & 30.199 & 5.547 & 24.65 & 615.86 & 197.22 & 2003 \\
\hline 315.0 & 587.9 & 6.688 & 7.524 & 32.003 & 5.878 & 26.13 & 634.07 & 209.00 & 2004 \\
\hline 296.0 & 555.5 & 5.731 & 6.447 & 27.423 & 5.037 & 22.39 & 595.10 & 179.09 & 2005 \\
\hline 480.0 & 639.2 & 4.385 & 4.933 & 20.981 & 3.854 & 17.13 & 669.52 & 137.02 & 2006 \\
\hline 603.0 & 965.5 & 6.507 & 7.320 & 31.136 & 5.719 & 25.42 & 1010.5 & 203.34 & 2007 \\
\hline 659.0 & 2033 & 16.95 & 19.07 & 81.097 & 14.90 & 66.20 & 2149.8 & 529.61 & 2008 \\
\hline 707.0 & 2412 & 30.30 & 34.09 & 145.01 & 26.63 & 118.4 & 2621.1 & 946.98 & 2009 \\
\hline 755.0 & 2228 & 41.19 & 46.34 & 197.09 & 36.20 & 160.9 & 2512.3 & 1287.14 & 2010 \\
\hline 840.0 & 2334 & 41.12 & 46.26 & 196.76 & 36.14 & 160.6 & 2618.0 & 1284.99 & 2011 \\
\hline 858.0 & 2589 & 30.21 & 33.99 & 144.57 & 26.55 & 118.0 & 2798.0 & 944.13 & 2012 \\
\hline 876.0 & 3670 & 50.82 & 57.17 & 243.18 & 44.67 & 198.5 & 4021.0 & 1588.14 & 2013 \\
\hline 959.0 & 2885 & 45.33 & 51.00 & 216.92 & 39.84 & 177.1 & 3198.0 & 1416.59 & 2014 \\
\hline 549.75 & 1494.63 & 19.48 & 21.91 & 93.20 & 17.12 & 76.08 & 1629.22 & 608.63 & المتوسط \\
\hline
\end{tabular}

** سعر الحدود أو السعر المجتمي لسلعة صادرات= السعر (F O B) - تكاليف الثحن والتأمين × سعر الصرف - (تكاليف النقل من الميناء إلى المصنع 3.6٪ + تكاليف التعبئة والنقل من المصنع للمزرعة 3.2\%). حيث أن: تكاليف الثحن= 12.5٪ من قيمة الصادرات. تكاليف التأمين= (قيمة الصادرات + تكاليف الثحن) × 2.5٪. المصدر: جمعت وحسبت من: الجهاز المركزي للتعبئة العامة والإحصاء، نثرة التجارة الخارجية، أعداد مختلفة

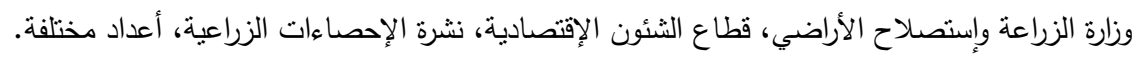




\begin{tabular}{|c|c|c|c|c|c|c|c|c|c|c|c|c|c|c|c|c|c|c|}
\hline & 8 & ह్టి & 串 & 密 & 总 & 总 & & ह్ & 总 & 总 & 号 & $\overrightarrow{\mathrm{Z}}$ & 켠 & & 壳 & d \\
\hline \multirow{7}{*}{$\begin{array}{c}1 \\
0 \\
3 \\
3 \\
3 \\
3 \\
7\end{array}$} & \multicolumn{2}{|c|}{ 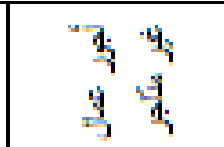 } & $\overrightarrow{\overrightarrow{\mathrm{u}}}$ & 漓 & 音 & 紊 & 辛 & 离 & 웅 & $\begin{array}{l}\text { 웅 } \\
\text { gi }\end{array}$ & 웅 & 官 & क्ष & क्ष & 号 & & 8 & 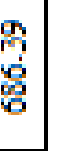 \\
\hline & \multicolumn{2}{|c|}{ 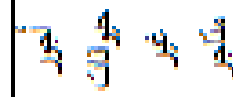 } & ị & ปै & 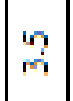 & 웅 & 임 & 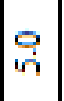 & 잉 & 옴 & 임 & 吕 & 잉 & 잉 & 잉 & 잉 & $\therefore$ & 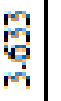 \\
\hline & 3 & & 年 & 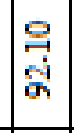 & 魚 & $\mid$ & $\begin{array}{l}8 \\
\dot{0} \\
\vdots\end{array}$ & 品 & 웅 & $\begin{array}{c}8 \\
\vdots \\
\vdots\end{array}$ & $\begin{array}{l}\stackrel{0}{0} \\
\stackrel{6}{\exists}\end{array}$ & 곡 & $\begin{array}{l}\text { 号 } \\
\text { 势 }\end{array}$ & 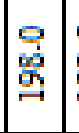 & 吕 & $\left|\begin{array}{l}2 \\
2 \\
0 \\
=\end{array}\right|$ & बें & ఫ్ర \\
\hline & 3 & & 年 & 高 & \begin{tabular}{|l|}
9 \\
g. \\
\end{tabular} & \begin{tabular}{|l}
9 \\
2 \\
2
\end{tabular} & $\begin{array}{l}8 \\
\dot{\alpha} \\
\alpha\end{array}$ & 輷 & 웅 & \begin{tabular}{|c|}
8 \\
$\vdots$ \\
$\vdots$
\end{tabular} & $\begin{array}{l}\stackrel{0}{0} \\
\stackrel{0}{7} \\
\end{array}$ & 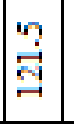 & $\begin{array}{l}2 \\
\text { के } \\
\text { ? }\end{array}$ & $\left.\begin{array}{l} \\
\vdots \\
\vdots \\
\vdots\end{array}\right]$ & $\begin{array}{l}\text { 吕 } \\
\text { 思 }\end{array}$ & 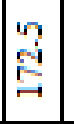 & वे. & 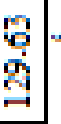 \\
\hline & $\frac{a}{3}$ & & \begin{tabular}{|l}
$n$ \\
2 \\
6 \\
6
\end{tabular} & 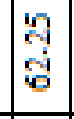 & $\begin{array}{l}8 \\
\text { जें }\end{array}$ & $\begin{array}{l}8 \\
0 \\
0\end{array}$ & 要 & 勇 & 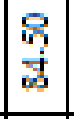 & \begin{tabular}{l}
8 \\
\hdashline \\
10
\end{tabular} & $\begin{array}{l}8 \\
\vdots \\
\vdots\end{array}$ & $\begin{array}{l}8 \\
2 \\
5\end{array}$ & 열 & : & 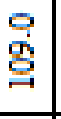 & 号 & 号 & $\begin{array}{c}5 \\
\mathbf{5} \\
\mathbf{5} \\
\end{array}$ \\
\hline & 索 & & 羿 & 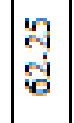 & \begin{tabular}{|l|}
8 \\
0 \\
0
\end{tabular} & $\begin{array}{l}8 \\
0 \\
0\end{array}$ & 量 & 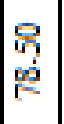 & $\mid \begin{array}{l}\frac{8}{5} \\
\text { 今. }\end{array}$ & \begin{tabular}{c}
8 \\
\hdashline \\
15
\end{tabular} & $\begin{array}{l}8 \\
\vdots \\
\vdots\end{array}$ & $\left|\begin{array}{l}8 \\
2 \\
5\end{array}\right|$ & 얼 & : & 웅 & 号 & 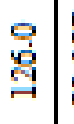 & 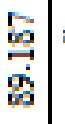 \\
\hline & & & 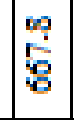 & 章 & 号 & 家 & : & g․ & & 离 & 竞 & $\mid \begin{array}{l}0 \\
\dot{3} \\
\text { o. }\end{array}$ & 官 & $\mid$ & 号 & & 寻 & త్ \\
\hline \multirow{4}{*}{$\begin{array}{l}3 \\
3 \\
3\end{array}$} & & & 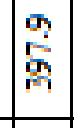 & 常 & 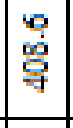 & $\begin{array}{l}\text { 웜 } \\
\text { ซ్ }\end{array}$ & $\begin{array}{l}\text { 是 } \\
\text { 守 }\end{array}$ & $\begin{array}{l}9 \\
\\
\\
\end{array}$ & 울 & 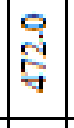 & 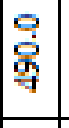 & 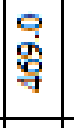 & 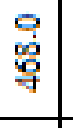 & | & 号 & & $\begin{array}{l}\text { 号 } \\
\text { 审 }\end{array}$ & $\begin{array}{l}\frac{1}{2} \\
\overline{6} \\
\frac{\sigma}{2}\end{array}$ \\
\hline & & 空 & वृ & 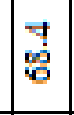 & $\overrightarrow{\dot{g}}$ & 官 & 章 & : & 웅 & 일 & 通 & 임 & 官 & 景: & 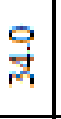 & & ติ่ & 羿 \\
\hline & & 雪党 & 嵒 & yิ & g웟 & 通 & 离 & 量 & 昜 & 㝵 & 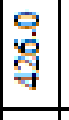 & 㝯 & $\begin{array}{l}0 \\
\vdots \\
i \\
i\end{array}$ & ํํํ & 菂 & 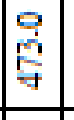 & वें & 志 \\
\hline & & 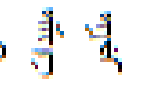 & 羿 & 올 & 羿 & 只 & 吕 & : & 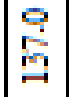 & 官 & 音 & 离 & 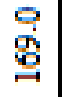 & 足 & 吕 & 官 & 嘼 & 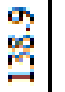 \\
\hline \multirow{4}{*}{ 氛 } & & 果 & 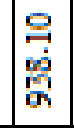 & 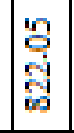 & $\mid \begin{array}{l}2 \\
2 \\
5 \\
5\end{array}$ & 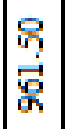 & $\begin{array}{l}8 \\
3 \\
2\end{array}$ & 量 & 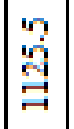 & 号 & $\mid \begin{array}{l}\text { 올 } \\
\text { 离 }\end{array}$ & 总 & $\begin{array}{l}9 \\
9 \\
9 \\
9\end{array}$ & 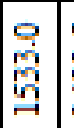 & בֶּ & $\mid \begin{array}{l}2 \\
\overrightarrow{7} \\
\stackrel{9}{-}\end{array}$ & 号 & 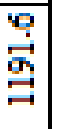 \\
\hline & & 2 & 今ี & 总 & $\stackrel{9}{\exists}$ & 吾 & 鸪 & 票 & 䍂 & 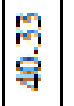 & 封 & $\mid$ & 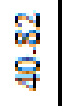 & 学 & 罢 & 周 & 常 & 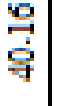 \\
\hline & & 粉 & 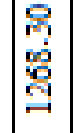 & 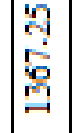 & 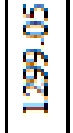 & 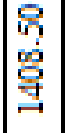 & 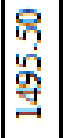 & 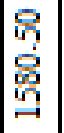 & $\mid$\begin{tabular}{l}
9 \\
0 \\
\hdashline \\
\hdashline \\
\hdashline
\end{tabular} & 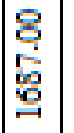 & 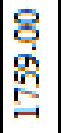 & 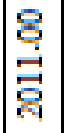 & $\begin{array}{l}\text { 号 } \\
\text { 总 }\end{array}$ & 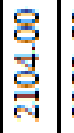 & $\begin{array}{l}\text { 命 } \\
\text { a }\end{array}$ & 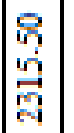 & $\begin{array}{l}8 \\
\text { สุ่ }\end{array}$ & 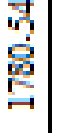 \\
\hline & & $\therefore$ & 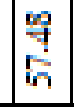 & 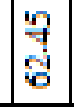 & 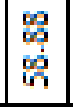 & $\begin{array}{l}7 \\
2 \\
2\end{array}$ & \begin{tabular}{|l|}
0 \\
8 \\
8
\end{tabular} & $\mid \begin{array}{l}2 \\
0 \\
8 \\
8\end{array}$ & \begin{tabular}{|l|} 
\\
0 \\
0
\end{tabular} & 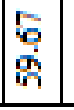 & 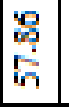 & $\begin{array}{l}\mathrm{y} \\
\overrightarrow{\mathrm{b}}\end{array}$ & $\begin{array}{l}\infty \\
\sigma \\
5\end{array}$ & 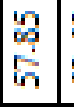 & $\begin{array}{l}6 \\
8 \\
8\end{array}$ & $\begin{array}{l}\vec{y} \\
\overrightarrow{5}\end{array}$ & 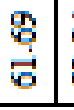 & 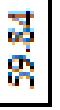 \\
\hline
\end{tabular}




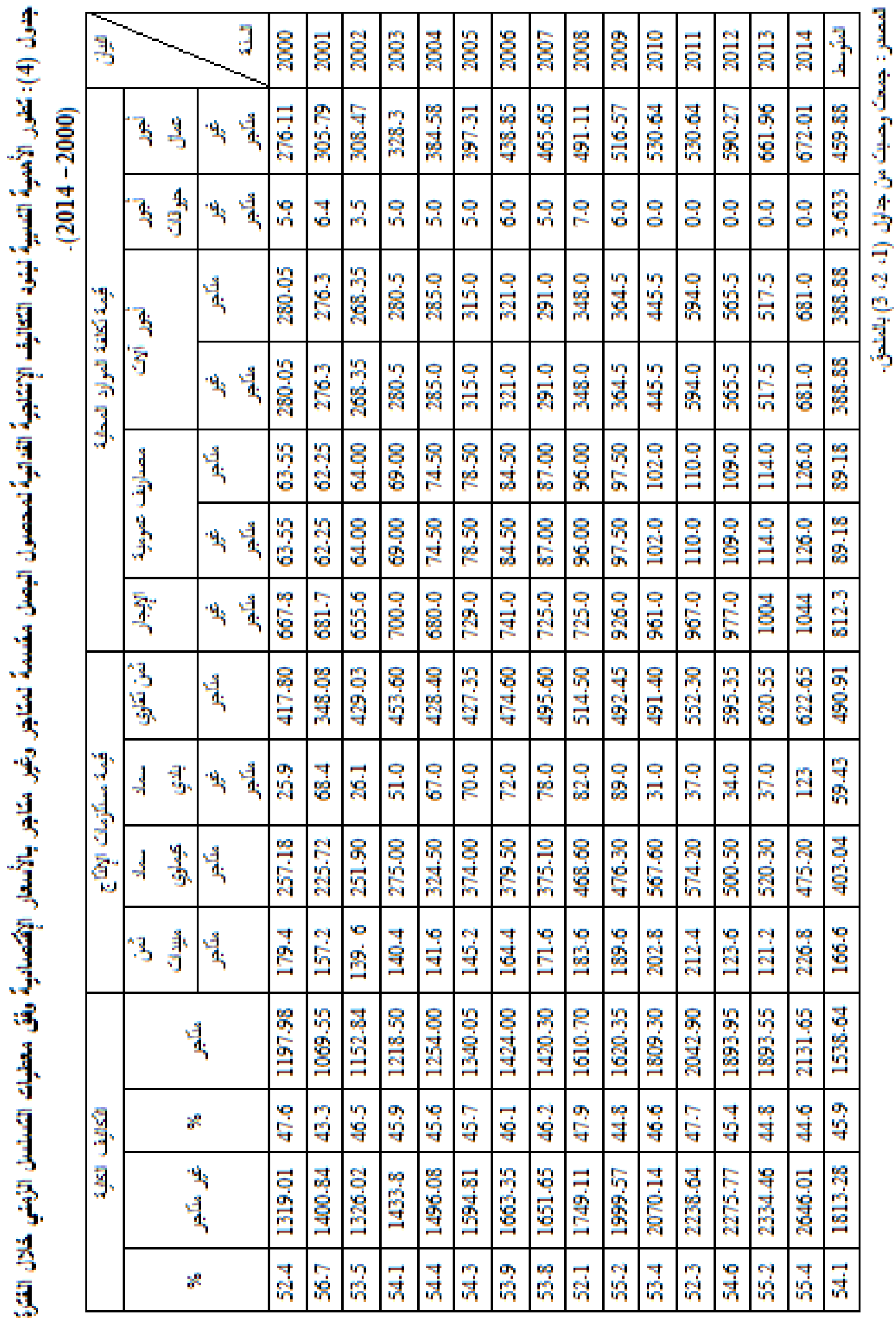


جدول (5): تطور المؤثرات الإقتصادية لمحصول البصل بالأسعار المالية والإتتصادية بالجنيه وفق معطيات التسلسل الزمني خلال الفترة (2000- 2014).

\begin{tabular}{|c|c|c|c|c|c|c|c|c|}
\hline \multicolumn{4}{|c|}{ القيم بالأسعار الإقتصادية } & \multicolumn{4}{|c|}{ القيم بالأسعار المالية } & \\
\hline تكاليف غير فياج & تكاليف متاجر & التكاليف الكلية & الإيراد الكلي & تكاليف غير فياجر فيها & متاجر فيها & التكاليف & الإيراد الكلي & \\
\hline 1319.01 & 1197.98 & 2516.98 & 3261.17 & 1268.3 & 938.10 & 2206.4 & 2501.01 & 2000 \\
\hline 1400.84 & 1069.55 & 2470.38 & 3902.12 & 1367.25 & 822.05 & 2189.3 & 2660.02 & 2001 \\
\hline 1326.02 & 1152.84 & 2478.86 & 4047.26 & 1299.05 & 907.35 & 2206.4 & 2724.13 & 2002 \\
\hline 1433.8 & 1218.50 & 2652.30 & 7231.57 & 1408.5 & 961.50 & 2370.0 & 2906.51 & 2003 \\
\hline 1496.08 & 1254.00 & 2750.08 & 7727.90 & 1495.5 & 990.50 & 2486.0 & 4140.99 & 2004 \\
\hline 1594.81 & 1340.05 & 2934.86 & 7199.24 & 1580.5 & 1051.5 & 2632.0 & 3836.16 & 2005 \\
\hline 1663.35 & 1424.00 & 3087.35 & 8217.83 & 1665.5 & 1125.5 & 2791.0 & 6170.88 & 2006 \\
\hline 1651.65 & 1420.30 & 3071.95 & 12991.7 & 1687.0 & 1140.0 & 2827.0 & 8113.97 & 2007 \\
\hline 1749.11 & 1610.70 & 3359.81 & 28193.8 & 1759.0 & 1281.0 & 3040.0 & 9140.33 & 2008 \\
\hline 1999.57 & 1620.35 & 3619.92 & 33021.2 & 2011.0 & 1279.0 & 3290.0 & 9680.24 & 2009 \\
\hline 2070.14 & 1809.30 & 3879.44 & 31000.7 & 2034.5 & 1403.5 & 3438.0 & 10506.6 & 2010 \\
\hline 2238.64 & 2042.90 & 4281.54 & 33428.2 & 2104.0 & 1533.0 & 3637.0 & 12031.3 & 2011 \\
\hline 2275.77 & 1893.95 & 4169.72 & 37274.7 & 2189.5 & 1422.5 & 3612.0 & 12351.8 & 2012 \\
\hline 2334.46 & 1893.55 & 4228.01 & 55333.5 & 2315.5 & 1451.5 & 3767.0 & 13208.3 & 2013 \\
\hline 2646.01 & 2131.65 & 4777.66 & 43652.1 & 2523.0 & 1567.0 & 4090.0 & 14511.6 & 2014 \\
\hline 1813.28 & 1538.64 & 3351.92 & 21098.9 & 1780.54 & 1191.6 & 2972.1 & 7632.25 & المتوسط \\
\hline
\end{tabular}

" الإيراد الكلي المالي= ( متوسط إنتاجية الفدان × متوسط السعر المالي المزرعي) .

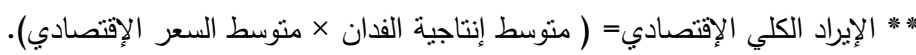
المصدر: جمعت وحسبت من جداول (1، 2، 3، 4) بالملحق. 


\title{
EFFECTIVE OF AGRICULTURAL POLICY ON ECONOMIC INDICATORS OF ONION CROP IN EGYPT
}

\author{
H. M. M. Seddik \\ Higher Institute of Agricultural Cooperation.
}

\begin{abstract}
Onions is considered to be one of the most important vegetable crops grown in Egypt, both at the level of domestic consumption or agricultural exports, where three seasons winter, summer, and Nile. Some areas average (101, 13, and 11) thousand acres respectively, representing approximately 50.2\%, 10.4\%, 8.8\% of total average yield of approximately 125 , 000 acres as an average of onion crop cultivated for the period (2000-2004). The research primarily targeted agricultural policy analysis for onions in Egypt, and defining the role of the State in the efficient use of available resources. Search also adopted data according to chronological data during the study period (2000-2014), through many sources such as the Ministry of agriculture and land re Central Agency for public mobilization and statistics, as well as many references and previous relevant studies. Search also adopted a generally descriptive and quantitative statistical analysis method to study the evolution of economic indicators to onions like time trend equations, as well as the policy analysis matrix (PAM). The main results are as follows: 1. the total area of the onion, the winter onion area shows statistically significant increase averaging about 6.8,6.63, thousand acres, while summer onions area shows a statistically significant decrease averaging about 0.424 thousand acres. 2. As for (human labour costs, automated labour costs, general expenses, rent) has taken a general trend towards moral whereof incrementally statistically $(41.88,18.1,9.06,30.23)$ pounds per acre. While animal cost trend whereof approximately 0.454 pounds/acre.3. As well as nominal protection coefficient outputs (outputs) was less than 1, this means that the State intervene to protect crop production in the local market4 - for nominal protection factor inputs (input) where he found stores was less than 1 which shows that input cost in domestic prices lower than the price limits. 5. for effective protection coefficient was found it was less than 1, this means that the added value of onions in domestic prices less than its counterpart in world prices, there are implicit taxes borne by producers of onions during the study period. 6. for domestic resource cost coefficient (comparative advantage) it has been less than 1, emphasizing the comparative advantage enjoyed by Egypt in crop production as a result of the lower cost of locally produced on expensive import. So the research is recommending:

1. Improvement in farm prices to onions crop to compensate for the continuous increase in production costs.

2. Address the disadvantages resulting from the policy of economic liberalization of markets and factors of production causing high costs of production.
\end{abstract}

Key words: Nominal protection coefficient- Effective protection coefficient- Domestic Resource Cost. 